\title{
Cerebellar dopamine D2 receptors regulate preference for social novelty
}

Laura Cutando ${ }^{1}$, Emma Puighermanal ${ }^{1 *}$, Laia Castell ${ }^{1}$, Pauline Tarot $^{1}$, Morgane Belle ${ }^{2}$, Federica Bertaso ${ }^{1}$, Margarita Arango-Lievano ${ }^{1}$, Fabrice Ango $^{1}$, Marcelo Rubinstein ${ }^{3}$, Alain Chédotal $^{2}$, Manuel Mameli ${ }^{4}$, Emmanuel Valjent $^{1}$

${ }^{1}$ IGF, Univ. Montpellier, CNRS, Inserm, F-34094 Montpellier, France.

${ }^{2}$ Institut de la Vision, Sorbonne Université, INSERM, CNRS, 17 Rue Moreau, F-75012 Paris, France.

${ }^{3}$ Instituto de Investigaciones en Ingeniería Genética y Biología Molecular, CONICET; FCEN, Universidad de Buenos Aires, Buenos Aires, Argentina; and Department of Molecular and Integrative Physiology, University of Michigan Medical School, Ann Arbor, Michigan, USA.

${ }^{4}$ Department of Fundamental Neuroscience, The University of Lausanne, Lausanne 1005, Switzerland.

\footnotetext{
* Present address Neurosciences Institute, Department of Cell Biology, Physiology and Immunology, Autonomous University of Barcelona, Bellaterra, Spain.
}

Correspondence should be addressed to Laura Cutando (E-mail: laura.cutandoruiz@igf.cnrs.fr) and Emmanuel Valjent (E-mail: emmanuel.valjent@igf.cnrs.fr)

Keywords: dopamine D2 receptors, cerebellum, Purkinje cells, preference for social novelty 


\section{Summary}

The cerebellum, a primary center involved in the control of sensorimotor tasks, also contributes to higher cognitive functions including reward, emotion and social interaction. The regulation of these behaviors has been largely ascribed to the monoaminergic system in limbic regions. However, the contribution of cerebellar dopamine signaling in the modulation of these functions remains largely unknown due to the lack of precise characterization of cerebellar dopaminoceptive neurons. By combining cell type-specific transcriptomic and histological analyses, 3D imaging and electrophysiology we demonstrate that cerebellar dopamine D2 receptors (D2R) in mice are preferentially expressed in Purkinje cells (PCs). While activation of D2R regulate synaptic efficacy onto PCs, their deletion or overexpression in PCs bidirectionally controls preference for social novelty without affecting motor functions. Altogether, these findings demonstrate novel D2R's roles in PC function and causally link cerebellar D2R levels of expression to social behaviors. 


\section{Introduction}

The cerebellum is a brain area that has long been considered to be solely involved in coordination of voluntary movements including the control of posture, balance and gaze orientation $^{1,2}$. However, increasing evidence indicates that the cerebellum also takes part in cognitive and emotional abilities as well as social interactions ${ }^{3-6}$. The control of these various components of motor, cognitive and affective behaviors is largely ascribed to its modular compartmentalization into functional independent units tightly modulated by monoaminergic inputs which signal arousal, salience and valence ${ }^{7-9}$. Accordingly, the dense plexus of tyrosine hydroxylase (TH)-positive fibers detected in all cerebellar layers and lobules ${ }^{10}$ provides an anatomical substrate to the influence of monoamines to cerebellar neuronal and synaptic activities. Early evidence suggested the presence of dopaminergic innervation in the cerebellum $^{11-15}$. However, its role within this structure remains largely enigmatic, in part because of the lack of and sometimes conflicting information regarding the distribution and the expression level of cerebellar DA receptors, in particular the dopamine D2 receptors (D2R). Thus, although seminal autoradiography and in situ hybridization studies revealed the existence of cerebellar D2R binding sites and D2R mRNA ${ }^{16-19}$, the use of the cerebellum as brain reference area in imaging studies ${ }^{20,21}$ questions the presence of cerebellar D2R. Clarifying this issue is of paramount importance to determine whether altered D2R expression leads to cerebellar dysfunctions frequently associated with motor, cognitive and social deficits observed in autism spectrum disorders (ASD), bipolar mood disorder, unipolar depression, posttraumatic stress disorder or schizophrenia ${ }^{22-31}$.

In this study, we combined cell type-specific molecular and imaging analyses, electrophysiology and mouse behavior to parse the role of $\mathrm{D} 2 \mathrm{R}$ in the cerebellum. We demonstrate that D2R are widely distributed throughout the cerebellar cortex (CC) and preferentially expressed by Purkinje cells (PCs). We show that D2R are functional in adult mice 
and regulate excitatory synaptic efficacy onto PCs. Using adenoviral approaches to selectively delete or overexpress D2R in PCs, we reveal that cerebellar D2R play a key role modulating the preference for social novelty without affecting the motor performance and the coordination of voluntary movements. Together, our findings unveil an unsuspected role of D2R in the cerebellum in the regulation of social interaction and may have important implications in the understanding of the etiology of socially-related disorders. 


\section{Results}

\section{Distribution of D2R in cerebellar neurons}

The lack of sensitive tools to detect low expression levels of D2R in the brain largely hampered the precise characterization of cerebellar D2R-containing cells. To determine their identity, we used BAC transgenic mice expressing fluorescent reporter protein under the control of Drd2 promotor $^{32}$. We first examined the expression pattern of GFP-positive cells in the cerebellum of D2-RCE mice. The analysis of GFP immunofluorescence allowed the identification of D2R-

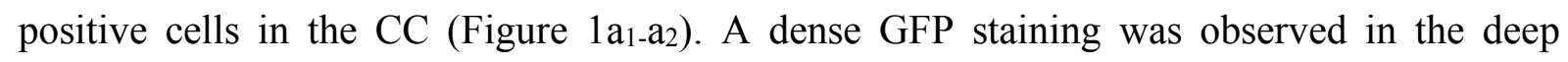
cerebellar nuclei (DCN) (Figures $1 \mathrm{a}_{1}$ and $\mathrm{S} 1 \mathrm{a}$ ) most likely corresponding to the terminals of PCs identified at higher magnification (Figure 1a $\mathrm{a}_{2}, \mathrm{a}_{3}$ ). To gain insights into the cellular characterization, we next examined the distribution of the cerebellar D2R-expressing cells in the D2-RiboTag mice which express the ribosomal protein Rpl22 tagged with hemagglutinin (HA) selectively in D2R-containing cells ${ }^{32}$. The analysis of HA-immunoreactivity in cerebellar slices (Figures $1 \mathrm{~b}$ and $\mathrm{S} 1 \mathrm{~b}$ ) or in cleared whole cerebellum using the iDISCO method ${ }^{33}$ (Video S1) confirmed that cerebellar D2R neurons were preferentially localized in the CC (Figure 1b and S1b). Although discontinuous pattern of GFP- or HA-positive labelled PCs were observed, they did not match the expression pattern of zebrin II, a well-established marker of PCs compartmentalization (Figure 1c). We also identified few D2R-expressing neurons in the molecular and granular layers (Figure $1 b_{2}-b_{3}$ ) as well as in the fastigial and interpositus nuclei (Figure S1b) suggesting that D2R were not restricted to PC layer. To further broaden our analysis, we determined the distribution and the percent of HA-positive cells in the lateral cerebellum (Simple lobule, Crus I, Crus II and Paramedian lobule) and in the cerebellar vermis (from lobule II to X) throughout the three cerebellar layers (Figures 1d-1e, S2, Table S1 and S2). Our quantification revealed that a high proportion (between $87 \%$ and $96 \%$ ) of CC HApositive cells were localized in PC layer compared to the molecular layer (between $3 \%$ and 
$12 \%$ ) while only few HA-expressing cells were detected in the granular layer (Figure 1e, S2 and Tables S1 and S2). Altogether, these results indicate that D2R are mostly expressed in the PC layer, with homogenous distribution throughout the cerebellar vermis and hemispheres as well as among lobules.

\section{Dopamine D2R are preferentially expressed by Purkinje cells}

After manual dissection of the CC (Figure S3), we next characterized the molecular identity of cerebellar D2R-positive cells in the CC by using the RiboTag methodology ${ }^{34}$. The enrichment of Drd2 and several gene products known to be expressed in PCs (Pcp2, Gad1, Slc32a1, Pvalb and Calb1) after HA-immunoprecipitation of $\mathrm{CC}$ extracts (pellet fraction) indicated the presence of mRNA encoding the D2R in PCs (Figure 2a-b). Double immunofluorescence analysis performed in D2-RiboTag and D2-RCE mice confirmed that a high proportion of HAand GFP-labeled cells co-localized with PCs markers including DARPP-32, G-substrate, calbindin-28kD (CB) and parvalbumin (PV) (Figures 2c-d, and S4). Intriguingly, HA-positive cells do not co-localized with calretinin (CR), a protein known to be expressed in cerebellar Granule cells $(\mathrm{GrCs})^{35}$. The de-enrichment in Calb2 observed after HA-immunoprecipitation further confirm the absence of D2R in GrCs (Figures 2b, S5a). The enrichment of Accn1 and Noslap gene products, two markers of GABAergic molecular layer interneurons (MLI-INs) ${ }^{36}$ as well as the presence of HA/PV cells in the molecular layer (yellow arrowheads) indicated that a fraction of baskets and stellate cells might express D2R (Figure 2b-c). Moreover, the significant enrichment in Acan but not in Grm2 and Grp suggested that D2R might also be expressed by a small proportion of Lugaro cells (LCs) but not by Golgi (GoCs) and Unipolar Brush cells (UBCs) (Figure 2b). The presence of Drd2 mRNA in these distinct neuronal populations was further confirmed by in situ hybridization. Indeed, Drd2 mRNA was found in cells expressing the gene encoding for the vesicular GABA transporter (Slc32al) in the CC 
including PCs and few MLI-INS (Figure 2e). By contrast, the lack of co-localization of HA and GFP with GFAP (Figure 2f-g) and Iba1 (Figure S5b) as well as the depletion of Cnp, Itgam and Gfap gene products found after HA-immunoprecipitation, indicated that D2R were not expressed in oligodendrocytes, microglia and glial cells (Figure S5c). This latter observation was confirmed by using Gfap-RiboTag mice in which no differences in Drd2 mRNAs levels were observed between the pellet and the input fractions (Figures S5d-e). We next determined the relative abundance of the two major D2R isoforms generated by alternative splicing, namely the D2R long (D2RL) and D2R short isoform (D2RS) ${ }^{37,38}$, known to display distinct pre and postsynaptic localization within the neuron ${ }^{39}$. To do so, we performed qRT-PCR analysis after HA-immunoprecipitation using designed primers including the sequence of the exon 6 deleted or not by alternative splicing. Two bands corresponding to both $\operatorname{Drd} 2$ isoforms $(\operatorname{Drd} 2 L \sim 250$ bp and $\operatorname{Drd} 2 S \sim 160 \mathrm{bp}$ ) were detected (Figure $2 \mathrm{~h}$ ). However, the high intensity of the band identifying the $\operatorname{Drd} 2 \mathrm{~L}$ isoform suggested that D2R were mainly expressed at postsynaptic compartments (Figure 2h). Finally, western blot analysis also indicated the presence of the D2R protein in the $\mathrm{CC}$ extracts of wild type mice (Figure $2 \mathrm{i}$ ). Altogether, our results indicate that D2R are preferentially expressed by PCs and to a lesser extent by MLI-INs and Lugaro cells.

\section{Activation of D2R modulate excitatory transmission in Purkinje cells}

Activation of D2R decreases AMPA-evoked responses in the striatum ${ }^{40}$. However, the effects of D2R activation on PCs AMPA-mediated transmission remain unknown. We first assessed the state of phosphorylation of the AMPA subunit GluA2 at S880 site (pS880-GluA2) -as a biochemical correlate of PCs excitability- following D2R activation (Figure S6a) ${ }^{41,42}$. Western blot analysis performed on cerebellar slices revealed a decrease of pS880-GluA2 $(22 \% \pm 8 \%)$ after bath application of the D2R agonist quinpirole $(10 \mu \mathrm{m})$, without modifying the total expression of the receptor (Figures 3a-b and S6b). This transient effect, observed 15 min after 
quinpirole application, suggested that direct D2R activation might decrease synaptic excitation onto PCs. To directly test this hypothesis, we recorded Parallel Fiber-evoked PC excitatory postsynaptic currents using cerebellar slices of wild type mice. Bath application of quinpirole $(10 \mu \mathrm{m})$ during 5 min produced a transient reduction of the PF-PC EPSCs amplitude $(20.6 \pm$ 4.5\%) compared to the initial baseline (Figure 3c). This decrease was independent of neurotransmitter release probability changes since no difference was found in the paired-pulse ratio facilitation measured at PF-PC synapses after application of quinpirole (Figure 3d). Together, these results suggest that D2R expressed at PCs are functional and modulate synaptic excitation onto PCs.

\section{Generation and validation of conditional D2R knockout mice in Purkinje cells}

To investigate the role of D2R expressed in PCs, we generated conditional PCs D2R knockout mice (PC-D2R-cKO). To do so, adeno-associated viral vectors expressing Cre-recombinase selectively in PCs were injected into the CC of Drd2f/f and Drd2+/+ mice. We first used an AAV serotype 8 (AAV8-Cmv-Cre-eGFP) known to be one of the most effective vectors to produce selective and high rate of transgene transduction in $\mathrm{PCs}^{43}$ (Figure 4). Because D2R are uniformly expressed throughout the CC, 9 stereotaxic injections of AAV8-Cmv-Cre-eGFP were performed on the CC of $\operatorname{Drd} 2+/+$ and $\operatorname{Drd} 2 f / f$ mice to ensure a large D2R invalidation (Figures 4a and S7). Three weeks after surgery, GFP and Cre expression were evaluated in the cerebellum of injected mice. Immunofluorescence analysis revealed that all eGFP positive cells co-localized with $\mathrm{CB}$ and Cre recombinase, thereby confirming the selective transduction in PCs (Figures 4b-c). Western blot analysis of Cre recombinase expression levels indicated that PCs were equally transduced in both control and PC-D2R-cKO mice (Figure 4d). Importantly, qRT-PCR analysis performed on isolated eGFP-positive PCs from mice injected with AAV8Cmv-Cre-eGFP indicated that the expression of Drd2 mRNA was strongly decreased in PC- 
D2R-cKO mice compared with the control group (Figure 4e). The invalidation of D2R was further confirmed by double immunofluorescence analysis performed in cerebellar slices of $\operatorname{Drd} 2 f / f$ mice injected with AAV8-Cmv-Cre-eGFP. Indeed, we found that D2R immunoreactivity observed at the PC layer (most likely corresponding to PCs) was strongly reduced in all eGFP-positive neurons (Figure 4f). Finally, the deletion of D2R from PCs was functionally efficient since the transient reduction of the PF-PC EPSCs amplitude induced by quinpirole $(22 \pm 2.2 \%)$ observed in eGFP-negative PCs was prevented in eGFP-positive PCs lacking D2R (Figure 4g-i). Of interest, paired-pulse ratio facilitation measured at PF-PC synapses was unaffected by the deletion of D2R in PCs (Figure 4j). Altogether, these results demonstrate that D2R expressed by PCs are involved in the regulation of their excitability upon D2R-agonist bath application and further validate our strategy to generate selective PC-D2RcKO mice.

\section{D2R expressed in Purkinje cells regulate preference for social novelty}

Control and coordination of voluntary movements (posture, balance, coordination, gaze orientation) are classically ascribed to PCs functions ${ }^{1}$. Because D2R modulate PCs excitatory transmission, we first assessed the impact of PCs D2R invalidation on locomotion, motor coordination and cerebellar learning. No difference in horizontal and vertical locomotor activity measured in a circular corridor was found between PC-D2R-cKO and control mice (Figure S8a). Moreover, PC-D2R-cKO mice had performance similar to control mice in accelerating rotarod, beam walking and coat-hanger tests, further indicating that motor routines and coordination were not altered in D2R-cKO (Figures S8b-d). In addition to its role in movement control, the cerebellum also takes part in cognitive abilities, regulation of emotions and social interactions ${ }^{5,6}$. We therefore tested whether D2R deletion from PCs might alter social interactions using the 3 -chamber test ${ }^{44}$. Sociability was first assessed by measuring the time 
mice spent exploring an object and an unfamiliar juvenile mouse (stranger 1, S1) (Figures 5a, $5 \mathrm{~b}$ and S9a). Both control and PC-D2R-cKO mice spent more time interacting with S1 than with the object (Figures 5a, 5b and S9a), a phenotype not due to the preference for one of the chambers towards the other neither for altered locomotor exploration (Figures S10a-e). Although no significant differences were observed between control and PC-D2R-cKO mice on the total time interacting with S1, PC-D2R-cKO mice tend to spend more time sniffing S1 than control mice suggesting that lack of D2R in PCs might enhance social interaction (Figures 5ab, S9a). We then evaluated preference for novel social stimuli. As expected, control mice spent more time in close interaction with novel intruder (stranger 2, S2) than with the familiar one (S1) (Figure 5c). The interaction time with S2 was significantly increased in PC-D2R-cKO mice, an effect independent of the entries and total time spent in S1 and S2 chambers (Figures $5 \mathrm{c}$ and S10f-h). To further characterize the preference for social novelty, the amount of time that the test mouse spent sniffing the novel intruder S2 was evaluated by epochs of 2 minutes. In wild type mice the time in interaction with S2 rapidly declined after 2 min (Figures 5d and $\mathrm{S} 9 \mathrm{~b})$. In contrast, PC-D2R-cKO mice spent more time interacting with the new mouse for the entire duration of the 10-min test (Figures $5 \mathrm{~d}$ and S9b), specially during the first $4 \mathrm{~min}$.

Similar results were obtained using an AAV in which the Cre recombinase is driven selectively in PCs by the minipromoter Ple155(Pcp2) (AAVDJ-Pcp2-Cre) $)^{45}$, further confirming that reduced D2R levels in PCs promote preference for social novelty (Figures S11 and S12).

\section{D2R overexpression in Purkinje cells impairs preference for social novelty}

Our previous results suggest that preference for social novelty might be intimately linked to PCs D2R levels. To directly test this hypothesis, enhancement of D2R signaling was achieved by injecting AAV8 virus expressing D2R and eGFP (AAV8-Cmv-mDrd2-IRES-eGFP) in the CC of C57/B16 mice (Figure 6a). Double immunolabeling of GFP and PCs markers (PV and 
CB) confirmed that virally expressed D2R were restricted to PCs (Figure 6b). Moreover, qRTPCR and western blot analyses showed that AAV8-Cmv-mDrd2-IRES-eGFP injected mice displayed a significant overexpression of $\operatorname{Drd} 2 \mathrm{mRNAs}$ compared to control mice injected with AAV8-Cmv-eGFP (Figure 6c). Importantly, the differential expression was also confirmed at the protein level by western blot (Figure 6d). Both D2R-overexpressed (PC-D2R-OE) and control mice showed comparable locomotor activity and motor coordination indicating that upregulation of D2R selectively in PCs does not affect cerebellar motor functions (Figure S13ad). Moreover, sociability was not affected by the overexpression of D2R in PCs since both groups spent equivalent amount of time interacting with S1 during the 10-min session (Figures 6e-f and S14a). In contrast, upregulation of D2R in PCs impaired social preference. Indeed, PC-D2R-OE mice spent significantly less time interacting with the new intruder (S2) compared to control mice (Figures $6 \mathrm{~g}-\mathrm{h}$ and S14b). Of interest, no difference in the total time in the S1 and S2 chambers was found between the two groups (Figure S15). On the other hand, time course of interaction analysis strongly suggested a rapid loss of social interest in PC-D2R-OE mice, especially during the epoch 4 to 6 min of the entire 10-min test (Figures $6 \mathrm{~h}$ and S14b). Altogether, these results endorse the causal link between cerebellar D2R expression levels and the modulation of social novelty behavior. 


\section{Discussion}

In this study, we demonstrate that cerebellar D2R neurons are homogenously distributed throughout the cerebellar vermis and hemispheres. We establish that D2R are preferentially expressed in PCs in which they contribute to the regulation of the excitatory transmission. We use different adenoviral approaches to selectively delete or overexpress D2R in PCs and demonstrate that D2R expression levels gate the preference for social novelty while having no effect on motor cerebellar functions such as coordination of voluntary movements.

Although several detailed brain mappings of $\mathrm{D} 2 \mathrm{R}$ at both mRNA and protein levels were established, contrasting results casted the doubt about the presence of D2R in the cerebellum. In this study, the use of BAC transgenic mice expressing fluorescent protein or taggedribosomes was determinant to parse the distribution and identity of cerebellar D2R-containing neurons. Thus, volume imaging of whole-mounted HA immunolabelling unambiguously identified PCs as the main cerebellar cell population expressing D2R. Such findings provide us a rational interpretation of observations made by using autoradiography in which D2R binding sites were detected in the superficial layers of $\mathrm{CC}^{16-19,46-48}$. In addition, the Ribotag methodology allowed us to detect the presence of Drd2 mRNA in PCs and in few ML-INs. This enrichment was confirmed using single molecule fluorescent in situ hybridization suggesting that probes or/and hybridization techniques previously used, were most likely not sensitive enough to detect low levels of $\operatorname{Drd} 2$ mRNA expression in a brain area such as the cerebellum ${ }^{18,49-51}$. Despite contrasting results were obtained regarding the cellular localization of $\mathrm{D} 2 \mathrm{R}^{52-54}$, we identified functional $\mathrm{D} 2 \mathrm{R}$ in the $\mathrm{CC}$. Indeed, $\mathrm{D} 2 \mathrm{R}$ activation produced a transient reduction of the PF-PC EPSCs amplitude, paralleled by a rapid decrease of GluA2 phosphorylation at $\mathrm{S} 880$ suggesting a role of $\mathrm{D} 2 \mathrm{R}$ in the modulation of synaptic excitation onto PCs. Supporting this idea, the slow inward current observed after a brief strong depolarization 
of PCs is prevented when D2R are blocked ${ }^{55}$. Further studies will determine to which extend D2R might also contribute to the regulation of short- and long-term cerebellar plasticity.

D2R play an essential role in dopamine-regulated motor control ${ }^{56,57}$. Although D2R's contribution in the regulation of motor behaviors was mainly ascribed to D2R distributed throughout the basal ganglia circuit, our results suggesting the presence of cerebellar D2R questioned their role in the control of posture, balance and coordination of voluntary movements. The generation of temporally-controlled deletion of D2R selectively in PCs (PCD2R-cKO) revealed that locomotion, fine motor control and cerebellar-learning performance did not appear to be modulated by D2R expressed in PCs, therefore contrasting with the phenotypes described in full or conditional striatal D2R knockout mice ${ }^{56-58}$. However, one cannot exclude that cerebellar D2R might participate to more selective cerebellar-dependent tasks such as the spontaneous eye blink reflex known to be impaired in some neuropsychiatric disorders associated with DA dysfunctions ${ }^{59,60}$. Instead, our data unveiled a role of cerebellar $\mathrm{D} 2 \mathrm{R}$ in social behaviors. Thus, $\mathrm{PC}-\mathrm{D} 2 \mathrm{R}-\mathrm{cKO}$ mice spent more time in close interaction with a new unfamiliar mouse than with a familiar one suggesting that reduced D2R levels in PCs may favor novel social contact. This trait did not result from a global social behavioral deficit since the quality of being social measured by comparing the time spent in interaction with an object and a new unfamiliar mouse was similar between control and PC-D2R-cKO mice. On the other hand, mice overexpressing D2R in PCs displayed a selective impairment in the preference for social novelty revealing a bidirectional control of cerebellar D2R over prosocial behaviors. However, it remains to be addressed whether D2R expressed in PCs may also modulate exploratory responses when other types of novel stimuli are presented, or conversely, if they are particularly involved in the modulation of social novelty behavior. Interestingly, growing evidence supports the hypothesis that distinct DA signaling in specific brain areas may interact 
dynamically to regulate different aspects of social behaviors. Thus, pharmacological blockade of D2R in the prefrontal cortex (PFC) selectively impaired social novelty discrimination ${ }^{61}$, while contrarily, blockade of dopamine D3 receptors (D3R) improved social memory and enhanced social novelty discrimination ${ }^{61,62}$. Finally, a similar enhancement in social recognition was observed following dopamine D1 receptor (D1R) activation in the PFC and the Nucleus Accumbens (NAc) ${ }^{63}$ where pro-social behavior required intact D1R signaling ${ }^{64}$.

Social interaction is a complex behavior that critically relies on the integrity of midbrain DA ventral tegmental area (VTA) neurons ${ }^{64-66}$. The dissection of neural circuits regulating social interaction indicate that several neural pathways converging onto different VTA DA neurons may regulate distinct components of social behaviors. Thus, excitatory inputs from the DCN to VTA neurons have been identified as an important pathway involved in the control of social reward ${ }^{6}$. More recently, the superior colliculus to VTA-Dorsal Striatum circuit has been proposed to regulate the orientation towards an unfamiliar conspecific mouse while the anterior cortex to VTA-NAc pathway would be involved in the modulation of conspecific interaction without affecting orienting behaviors ${ }^{67}$. Interestingly, our results indicate that the regulation of pro-social behavior relied in part of DA signaling within the CC. Such findings naturally question the source of cerebellar DA that could contribute to these effects. Early tract-tracing studies indicated that midbrain VTA DA neurons project to the cerebellum ${ }^{12,13}$ (but see $^{68}$ ). VTA DA neurons projecting back to the cerebellum would form a closed-loop allowing a tight and precise modulation of social behaviors. Supporting this hypothesis, VTA DA neurons projecting to the $\mathrm{CC}$ innervate predominantly the Crus I lobule ${ }^{12}$, which has been implicated in the control of social behavior and found impaired in patients with $\mathrm{ASD}^{23,69}$ Additional possible sources of DA in the CC include a small fraction of PCs expressing $\mathrm{TH}^{70,71}$ as well as noradrenergic fibers ascending from the locus coeruleus, which have been previously shown to 
release DA in the dorsal hippocampus ${ }^{72}$ and the paraventricular thalamic nucleus ${ }^{73}$. Whether these distinct sources of DA might engage cerebellar D2R in the control of movements, cognition and emotions remain to be determined.

In summary our results reveal an unexpected role of cerebellar D2R in the social novelty preference. Future studies are needed to assess the role of cerebellar D2R in the regulation of some specific components of social contact (e.g. the time following behavior or the nose-tonose contact), as well as the aggressive behavior or the reinforcing properties of social interaction. Whether D2R expressed by PCs may participate to reward processing through the modulation of the DCN-VTA pathway ${ }^{6}$ still remain to be established. 


\section{Materials and Methods}

\section{Animals}

This study was conducted using male and female wild-type C57B1/6j (Charles River), Drd2$R C E$ (abbreviated as D2-RCE in the manuscript), RiboTag::Drd2-Cre (abbreviated as D2RiboTag in the manuscript), RiboTag::Gfap-CreERT2 (abbreviated as Gfap-RiboTag in the manuscript), RiboTag::Drd2-floxed and Drd2-floxed mice of 10-15 weeks old. Drd2-RCE mice were produced by crossing the hemizygous BAC Drd2-Cre mice (C57B1/6j, founder ER44) generated by GENSAT (Gene Expression Nervous System Atlas) at the Rockefeller University (New York, NY) ${ }^{74}$ with the R26R CAG-boosted EGFP:LoxP (RCE:LoxP) mice as it was previously described ${ }^{32}$. Homozygous female RiboTag-floxed ${ }^{75}$ mice from The Jackson Laboratory were crossed with heterozygous male Drd2-Cre and tamoxifen-inducible GfapCreERT2 mice to generate RiboTag::Drd2-Cre and RiboTag::Gfap-CreERT2 mice ${ }^{32}$. Similarly, homozygous female RiboTag:floxed were crossed with homozygous Drd2-floxed mice (from Dr. Marcelo Rubinstein laboratory). First-generation of mice RiboTag::Drd2-floxed heterozygous for the Drd2-floxed gene (RiboTag::Drd2-f/+) were crossed a second time with homozygous Drd2-floxed (Drd2-f/f) mice to generate RiboTag::double-Drd2-floxed mice (RiboTag::Drd2-f/f). For behavioral experiments, wild-type C57B1/6j, RiboTag::Drd2-f/f, RiboTag::Drd2-+/+, Drd2-f/f and Drd2-+/+ mice were used.

Animals were maintained in a 12-hour light/dark cycle, in stable conditions of temperature and humidity, with food and water ad libitum. All experiments were in accordance with the guidelines of the French Agriculture and Forestry Ministry for handling animals (authorization number/license D34-172-13). All experiments were conducted blindly to the experimenter and mice were arbitrarily assigned to both viral and pharmacological treatments. The number of animals used in each experiment is reported in the figure legends and the in the statistic report. 
No statistical methods were used to predetermine sample sizes, but our sample sizes are comparable to those generally used in the field.

\section{Drugs and Treatments}

Quinpirole hydrochloride was purchased from Tocris Bioscience (Cat \#1061) and tamoxifen $(100 \mathrm{mg} / \mathrm{kg})$ from Sigma-Aldrich. Tamoxifen was administered intraperitoneally in a volume of $10 \mathrm{ml} / \mathrm{kg}$ and dissolved in sunflower oil/ethanol (10:1) to a final concentration of $10 \mathrm{mg} / \mathrm{ml}$. To induce the Cre expression in the RiboTag::Gfap-CreERT2 mice, tamoxifen (100 mg / kg) was administered during 3 consecutive days intraperitoneally in a volume of $10 \mathrm{ml} / \mathrm{kg}$.

\section{Stereotaxic injection into the cerebellum}

Surgeries were performed on 10-12 weeks old RiboTag:: Drd2-f/f, RiboTag:: Drd2-+/+, Drd2$f / f, \operatorname{Drd} 2-+/+$ mice and wild type mice. Animals were anesthetized with a mixture of ketamine (Imalgene 500, $50 \mathrm{mg} / \mathrm{ml}$, Merial), $0.9 \% \mathrm{NaCl}$ solution (weight/vol) and xylazine (Rompun $2 \%, 20 \mathrm{mg} / \mathrm{ml}$, Bayer) $(2: 2: 1$, i.p., $0.1 \mathrm{ml} / 30 \mathrm{~g})$ and mounted on a stereotaxic apparatus. The microinjection needle was connected to a $10 \mu$ Hamilton syringe and filled with $6 \mu$ of the adeno-associated viruses AAV8-Cmv-Cre-eGFP (titer 7.2E+13 GC/ml; Vector Biolabs \#7062) (Great Valley Parkway, Malvern, PA), AAV8-Cmv-eGFP (titer 1E+13 GC/ml; Vector Biolabs \#7061) (Great Valley Parkway, Malvern, PA), AAV8-Cmv-m-Drd2-IRES-eGFP (titer 5.3E+13 GC/ml; Vector Biolabs; Lot. 180507\#25) (Great Valley Parkway, Malvern, PA) and AAVDJPcp2-Cre (produced in our laboratory). Viral vectors were injected at 9 sites of the CC in order to infect the maximal cerebellar surface. At a rate of $100 \mathrm{nl} / \mathrm{min}$, a total volume of $600 \mathrm{nl}$ were injected at each site during $6 \mathrm{~min}$. The injector was left in place for an additional $5 \mathrm{~min}$ before it was removed to allow the diffusion of viral particles away from the site of injection. The coordinates used were: (AP: $-5.65 \mathrm{~mm}, \mathrm{ML}: 0 \mathrm{~mm}$, DV: $-1.7 \mathrm{~mm}$ ), (AP: $-6,12 \mathrm{~mm}$, ML: -1.8 
mm, DV: $-2 \mathrm{~mm}),(\mathrm{AP}:-6.12 \mathrm{~mm}, \mathrm{ML}:+1.8 \mathrm{~mm}$, DV: $-2 \mathrm{~mm}),(\mathrm{AP}:-6.36 \mathrm{~mm}, \mathrm{ML}:-2.5 \mathrm{~mm}$, DV: -2.8), (AP: -6.36 mm, ML: +2.5 mm, DV: -2.8), (AP: -6.72 mm, ML: $-1.2 \mathrm{~mm}, \mathrm{DV}:-2)$, (AP: $-6.72 \mathrm{~mm}, \mathrm{ML}:+1.2 \mathrm{~mm}, \mathrm{DV}:-2.4)$, (AP: $-7.08 \mathrm{~mm}$, ML: $0 \mathrm{~mm}, \mathrm{DV}:-2.4),(\mathrm{AP}:-7.56$ $\mathrm{mm}, \mathrm{ML}: 0 \mathrm{~mm}, \mathrm{DV}:-2.7)$. Wounds of mice were sealed by suture (Coated-Vicryl Violet 75 cm, 3/8 circle CC-1 $13 \mathrm{~mm}$; \#JV1012; Phymep). Animals were then returned to their home cages for a recovery period of 21 days before behavioral evaluation.

\section{AAVDJ-Pcp2-Cre production}

For AAVDJ-PCp2-Cre production we followed the protocol previously described ${ }^{76}$. The AAV plasmid with Pcp2 (Ple155) minipromoter driving expression of iCre was used (pEMS1986, plasmid \#49117. Addgene). We selected the minipromoter Ple155 because it selectively transduces PCs as it was previously described ${ }^{45}$. The promoter fragment was isolated via restriction with EcoRI and HindIII enzymes. The viral production was performed with the DJpackaging system (Cell Biolabs).

\section{Tissue Preparation and Immunofluorescence}

Tissue preparation and immunofluorescence were performed as previously described ${ }^{77}$. Mice were rapidly anaesthetized with euthasol (360 mg/kg, i.p., TVM lab, France) and transcardially perfused with 4\% (weight/vol) paraformaldehyde in $0.1 \mathrm{M}$ sodium phosphate buffer ( $\mathrm{pH} 7.5)$. Brains were post-fixed overnight in the same solution and stored at $4^{\circ} \mathrm{C}$. Forty- $\mu \mathrm{m}$ thick sections were cut with a vibratome (Leica, France, RRID:SCR_008960) and stored at $-20^{\circ} \mathrm{C}$ in a solution containing 30\% (vol/vol) ethylene glycol, 30\% (vol/vol) glycerol and $0.1 \mathrm{M}$ sodium phosphate buffer, until they were processed for immunofluorescence. Cerebellar sections were identified using a mouse brain atlas (Franklin and Paxinos, 2007) and sections comprised between $-5.80 \mathrm{~mm}$ and $-7.0 \mathrm{~mm}$ from bregma were included in the analysis. Sections were 
processed as follows: free-floating sections were rinsed three times $10 \mathrm{~min}$ in Tris-buffered saline (50 mM Tris-HCL, $150 \mathrm{mM} \mathrm{NaCl}$, pH 7.5). After $20 \mathrm{~min}$ incubation in $0.1 \%$ (vol/vol) Triton X-100 in TBS, sections were rinsed in TBS again during 10 min and blocked for $1 \mathrm{~h}$ in a solution of $3 \%$ BSA in TBS. Cerebellar sections were then incubated 72 hours at $4{ }^{\circ} \mathrm{C}$ with the primary antibodies (Table 1) diluted in a TBS solution containing in $1 \%$ BSA and $0.15 \%$ Triton X-100. Sections were rinsed three times for $10 \mathrm{~min}$ in TBS and incubated for $60 \mathrm{~min}$ with goat Cy3-coupled anti-rabbit (1:500, Thermo Fisher Scientific Cat\# 10520, RRID:AB_2534029), goat Alexa Fluor 488-coupled anti-chicken (1:500, Thermo Fisher Scientific Cat\#A-11039, RRID:AB_2534096), goat Alexa Fluor 488-coupled anti-mouse (1:500, Thermo Fisher Cat\#A-11001, RRID:AB_2534069), goat Alexa Fluor 488-coupled antirabbit (1:500, Life Technologies Cat\#A-11034, RRID:AB_2576217), goat Cy5-coupled antimouse (1:500, Thermo Fisher Scientific Cat\#A-10524, RRID: AB_2534033), donkey Cy3conjugated anti-chicken (1:500, Jackson Immunoresearch Cat\#03-165-155, RRID:AB_2340363), goat Cy3-coupled anti-mouse (1:500, Jackson Immunoresearch Cat\#115165-003, RRID:AB_2338680) antibodies. Sections were rinsed for 10 minutes (twice) in TBS and twice in Tris-buffer (1 M, pH 7.5) before mounting in DPX (Sigma-Aldrich). Confocal microscopy and image analysis were carried out at the Montpellier RIO Imaging Facility. Images covering the entire cerebellum and double-labeled images from each region of interest were acquired using sequential laser scanning confocal microscopy (Zeiss LSM780). Photomicrographs were obtained with the following band-pass and long-pass filter setting: alexa fluor 488/Cy2 (band pass filter: 505-530), Сy3 (band pass filter: 560-615) and Сy5 (longpass filter 650). All parameters were held constant for all sections from the same experiment. Three-four slices per mouse were used in all immunofluorescence analyses $(n=3$ mice / staining). 
Table 1: Antibodies used in immunofluorescence

\begin{tabular}{|c|c|c|c|c|c|}
\hline Antigen & Host & Dilution & Supplier & Catalog N & RRID \\
\hline GFP & Chicken & $1: 1000$ & Life Technologies & A10262 & RRID:AB_2534023 \\
\hline DARPP-32 & Rabbit & $1: 1000$ & Cell Signaling & \#2306S & RRID:AB_823479 \\
\hline Parvalbumin & Rabbit & $1: 1000$ & Swant & PV25 & RRID:AB 2315235 \\
\hline VGluT1 & Rabbit & $1: 1000$ & Abcam & ab77822 & RRID:AB 2187677 \\
\hline GFAP & Chicken & $1: 1500$ & Abcam & Ab4674 & RRID:AB_304558 \\
\hline HA & Mouse & $1: 1000$ & Biolegend & 901502 & RRID:AB 2565007 \\
\hline HA & Rabbit & $1: 1000$ & Rockland & $600-401-384$ & RRID:AB_217929 \\
\hline $\begin{array}{l}\text { Red Fluorescent } \\
\text { Protein (RFP) }\end{array}$ & Rabbit & $1: 1000$ & MBK & PM005 & RRID:AB_591279 \\
\hline Zebrin-II & Mouse & $1: 750$ & $\begin{array}{l}\text { Provided by Dr. } \\
\text { Philippe Isope }\end{array}$ & \multicolumn{2}{|c|}{$\begin{array}{l}\text { Gift of Richard Hawkes, Calgary. } \\
\text { Brochu et al., } 1990\end{array}$} \\
\hline Iba1 & Rabbit & $1: 1000$ & Wako & $019-19741$ & RRID:AB_839504 \\
\hline $\mathrm{NeuN}$ & Mouse & $1: 1000$ & Millipore & MAB377 & RRID:AB_2298772 \\
\hline VGAT & Rabbit & $1: 1000$ & Millipore & AB5062P & RRID:AB_2301998 \\
\hline VGluT2 & Mouse & $1: 1000$ & Abcam & ab84103 & RRID:AB_10674784 \\
\hline CB1R & Rabbit & $1: 1000$ & Frontier Science & $\begin{array}{l}\text { CB1-Rb- } \\
\text { Af380 }\end{array}$ & RRID:AB_2571591 \\
\hline Calbindin-28k & Rabbit & $1: 1000$ & Swant & CB38 & RRID:AB_2721225 \\
\hline Calretinin & Rabbit & $1: 1000$ & Swant & $7699 / 3 \mathrm{H}$ & RRID:AB_10000321 \\
\hline G-Substrate & Rabbit & $1: 500$ & $\begin{array}{l}\text { Provided by Dr. } \\
\text { Endo Shogo }\end{array}$ & \multicolumn{2}{|l|}{ Endo, S., 1999} \\
\hline Gad2 (Gad65) & Rabbit & $1: 1000$ & Synaptic System & 198102 & RRID:AB_2107893 \\
\hline $\mathrm{D} 2 \mathrm{R}$ & Rabbit & $1: 1000$ & Frontier Institute & $\begin{array}{l}\text { D2R-Rb- } \\
\text { Af960 }\end{array}$ & RRID : AB_2571596 \\
\hline GFAP & Rabbit & $1: 1000$ & Dako & N1506 & RRID:AB_10013482 \\
\hline Cre & Rabbit & $1: 1500$ & Millipore & $69050-03$ & RRID:AB_10806983 \\
\hline
\end{tabular}

\section{Tissue Collection}

Mice were killed by cervical dislocation and the heads were immersed in liquid nitrogen for 4 sec. The brains were then removed and sectioned on an aluminum block on ice and the whole cerebellum was rapidly isolated from the stem brain. For the cerebellar cortex and the deep cerebellar nuclei dissection, brains were placed in a matrix and both regions were isolated from $\sim 1$-mm thick coronal section located between $5.80 \mathrm{~mm}$ and $6.80 \mathrm{~mm}$ posterior to bregma. 


\section{Western Blot}

Protein quantification and western blots were performed following the protocol previously described $^{77}$. The whole cerebellum, CC, DCN and cerebellar slices were sonicated in $300 \mu 1$, $200 \mu \mathrm{l}$ and $150 \mu \mathrm{l}$ and $120 \mu \mathrm{l}$ of $10 \%$ sodium dodecyl sulfate (SDS) and boiled at $100^{\circ} \mathrm{C}$ for 10 min. In each experiment, samples from different animal groups, treatments or brain regions to be compared were processed in parallel to minimize interassay variations. Following the manufacturer's instructions, protein contents for each sample were determined by BCA protein assay (Pierce) (Lot\# RG235624; Thermo Scientific). Equal amounts of cerebellar lysates were mixed with denaturing 4 Laemmli loading buffer. Samples with equal amounts of total protein (50 $\mu \mathrm{g}$ per lane for Figure $2 \mathrm{i}$ and $6 \mathrm{~d} ; 25 \mu \mathrm{g}$ per lane for Figure 3a, S6b, 4d and S11c; $20 \mu \mathrm{g}$ per lane Figure S3a) were separated in 11\% SDS-polyacrylamide gel before electrophoretic transfer onto Immobilon-P membranes (\#IPVH00010; Millipore). Membranes were cut horizontally, at different molecular weights to be analyzed with different primary antibodies. Using $4 \%$ bovine serum albumin (BSA) in 0.1M PBS, membranes were blocked for $45 \mathrm{~min}$. Next, membranes were incubated for $2 \mathrm{~h}$ with the primary antibodies (Table 2).

To detect the primary antibodies, horseradish peroxidase-conjugated antibodies (1:10000) from Cell Signaling Technology to rabbit (Cat\# 7074S; RRID: RRID:AB_2099233) or mouse (Cat\# 7076S; RRID: AB_330924) were used at and visualized by enhanced chemiluminescence detection (Luminata Forte Western HRP Substrate; Millipore, Cat\# WBWF0500). The optical density of the relevant immunoreactive bands was measured after acquisition on a ChemiDoc Touch Imaging System (Bio-Rad) controlled by Image Lab software version 3.0 (Bio-Rad). Representative cropped immunoblots for display were processed with Adobe Illustrator CS6. For quantitative purposes, the optical density values of active phospho-specific antibodies were normalized to the detection of non-phospho-specific antibodies or to $\beta$-actin or GAPDH values in the same sample and expressed as a percentage of control treatment or group. 
Table 2: Antibodies used in western blot experiments

\begin{tabular}{|l|l|l|l|l|l|}
\hline Antigen & Host & Dilution & Supplier & Catalog N & RRID \\
\hline D2R & Rabbit & $1: 500$ & Frontier Institute & $\begin{array}{l}\text { D2R-Rb- } \\
\text { Af960 }\end{array}$ & RRID :AB_2571596 \\
\hline mGluR1 & Rabbit & $1: 1000$ & Millipore & $07-617$ & RRID:AB_310755 \\
\hline GluA1 & Rabbit & $1: 1000$ & Millipore & AB15044 & RRID:AB_2113602 \\
\hline VGluT1 & Rabbit & $1: 1000$ & Abcam & Ab77822 & RRID:AB_2187677) \\
\hline VGluT2 & Rabbit & $1: 1000$ & Abcam & Ab84103 & RRID:AB_10674784 \\
\hline VGAT & Rabbit & $1: 1000$ & Synaptic System & 131013 & RRID:AB_2189938 \\
\hline Calbindin-28k & Rabbit & $1: 1000$ & Swant & CB38 & RRID:AB_2721225 \\
\hline CB1R & Rabbit & $1: 1000$ & Frontier Science & $\begin{array}{l}\text { CB1-Rb- } \\
\text { Af380 }\end{array}$ & RRID:AB_2571591 \\
\hline Gapdh & Mouse & $1: 40000$ & Santa Cruz & SC-32233 & RRID:AB_627679 \\
\hline $\begin{array}{l}\text { Pospho- } \\
\text { GluA2S880 }\end{array}$ & Rabbit & $1: 1000$ & Abcam & Ab52180 & RRID:AB_880227 \\
\hline GluA2 & Mouse & $1: 1000$ & Millipore & MAB397 & RRID:AB_11212990 \\
\hline B-Actine & Mouse & $1: 40000$ & Abcam & Ab6276 & RRID:AB_2223210 \\
\hline Cre & Rabbit & $1: 500$ & Millipore & $69050-03$ & RRID:AB_10806983 \\
\hline
\end{tabular}

\section{Cerebellar slices preparation and D2R stimulation by quinpirole}

Mice were sacrificed by deep anesthesia with isoflurane inhalation followed by decapitation.

The brain was quickly removed and immersed in ice-cold ACSF containing the following (in $\mathrm{mm}): 126 \mathrm{NaCl}, 3 \mathrm{KCl}, 1.25 \mathrm{NaH} 2 \mathrm{PO} 4,1.3 \mathrm{MgSO} 4,26 \mathrm{NaHCO} 3,2.5 \mathrm{CaCl}$, and 10 glucose equilibrated with $95 \%$ O2 plus 5\% CO2. Cerebellar sagittal slices (300 $\mu \mathrm{m}$-thick) were cut by using a vibratome (Campden Instruments, UK) and pooled in $10 \mathrm{ml}$ of ice-cold ACSF buffer. All the solutions used in this experiment were continuously bubbled with $95 \% \mathrm{O} 2$ and $5 \% \mathrm{CO} 2$. Once the slices were prepared, they were transferred individually in $6 \mathrm{ml}$ of cold oxygenated ACSF buffer. Cerebellar slices were incubated for $5 \mathrm{~min}, 15 \mathrm{~min}$ or $30 \mathrm{~min}$ in ACSF mixed with $6 \mu$ of either quinpirole hydrochloride (Tocris; Cat\# 1061, to a final concentration of 10 $\mu \mathrm{M}$ ) or distilled water (control). Afterwards, slices were sonicated with $120 \mu \mathrm{l}$ of $10 \%$ sodium dodecyl sulfate (SDS) and boiled at $100^{\circ} \mathrm{C}$ for $10 \mathrm{~min}$ to perform Western blot analysis as described above. 


\section{Polyribosome Immunoprecipitation and RNA extraction}

HA-tagged-ribosome immunoprecipitation in the whole cerebellum and CC of RiboTag::Drd2Cre mice was performed as it was previously described ${ }^{78}$ using anti-HA antibody (5ul/sample; Biolegend; Cat\#901502) and magnetic beads (Invitrogen, \#100.04D). Total RNA contained in the pellet fraction was extracted from ribosome-mRNA complexes using RNeasy Microkit (Qiagen; Cat\#74004) and from the input fraction using the RNAeasy Minikit (Qiagen; Cat\#74104) following manufacturer's instructions. Quality and quantity of RNA samples were both assessed using the Nanodrop 1000 spectrophotometer. Between 4 and 6 biological replicates, each one composed of a pool of 2 mice, were used for qRT-PCR analysis.

For the RNA extraction from the CC and DCN (Figure S3c) we used the RNAeasy Minikit (Qiagen; Cat\#74104) following manufacturer's instructions.

\section{cDNA Synthesis and Quantitative Real-Time PCR}

After RNA extraction from pellet and the input fractions of CC RiboTag::Drd2-Cre mice, synthesis of cDNA was performed as it was previously described ${ }^{34}$ by using the SuperScript VILO cDNA synthesis kit (Invitrogen) in one cycle program consisting on $10 \mathrm{~min}$ at $25^{\circ} \mathrm{C}, 60$ min et $42^{\circ} \mathrm{C}, 5 \mathrm{~min}$ at $25^{\circ} \mathrm{C}$ and with a final extension period of $5 \mathrm{~min}$ at $4^{\circ} \mathrm{C}$. Resulting cDNA was used for quantitative real-time PCR (qRT-PCR), using SYBR Green PCR master mix on the LC480 Real-Time PCR System (Roche) and the primer sequences indicated in Table 3. Analysis was performed using LightCycler 480 Software (Roche). The immunoprecipitated RNA samples (pellet) were compared to the input samples in each case. Results are presented as $\%$ of change of the pellet fraction versus the input for each gene and normalized to the housekeeping gene $\operatorname{Tbp} 2 a$. For the analysis of the genes expressed in the cerebellar cortex and deep cerebellar nulei, results are presented as linearized Ct-values normalized to housekeeping Tbp $2 a$ and the $\Delta \Delta \mathrm{Ct}$ method was used to give the fold change. 4-6 biological replicates are used in these experiments. 
To determine which $\operatorname{Drd} 2$ isoform is the most abundant in the $\mathrm{CC}$, primers were designed to recognize the presence or absence of exon 6 (Table 3). After the qRT-PCR analysis, pellet samples were collected from the qRT-PCR plate and mixed with Purple Gel Loading Dye (BioLabs, Cat\#B7025S) to be load on 1\% agarose gel. Two band were detected in the gel, the upper band (245bp) corresponds with the long isoform of $\operatorname{Drd} 2$ gene, whereas the lower band (158 bp) corresponds to short isoform of $\mathrm{Drd} 2$ gene.

Table 3. Sequences of primers

\begin{tabular}{|c|c|}
\hline $\operatorname{Drd2}$ & $\begin{array}{l}\text { Sense, CCTTCATCGTCACCCTGCTGG } \\
\text { Antisense, CTCCATTTCCAGCTCCTGAG }\end{array}$ \\
\hline Gfap & $\begin{array}{l}\text { Sense, AGCGAGCGTGCAGAGATGA } \\
\text { Antisense, AGGAAGCGGACCTTCTCGAT }\end{array}$ \\
\hline Cnp & $\begin{array}{l}\text { Sense, GCTGCACTGTACAACCAAATTCTG } \\
\text { Antisense, ACCTCCTGCTGGGCGTATT }\end{array}$ \\
\hline Itgam & $\begin{array}{l}\text { Sense, ATGGTCACCTCCTGCTTGTGAG } \\
\text { Antisense, CCAGCAGTGATGAGAGCCAAGA }\end{array}$ \\
\hline Pcp2 & $\begin{array}{l}\text { Sense, TGCAGGGCGATCGGATGGAGGAG } \\
\text { Antisense, TGAGGGGTGAGCAGGGGTTGAGG }\end{array}$ \\
\hline Grm2 & $\begin{array}{l}\text { Sense, CCATCTTCTACGTCACCTCC } \\
\text { Antisense, AGGAACAAGCTGGGATCCAG }\end{array}$ \\
\hline NeuroD1 & $\begin{array}{l}\text { Sense, GCAGCTCTGGAGCCCTTCTT } \\
\text { Antisense, GCGGCACCGGAAGAGAAGAT }\end{array}$ \\
\hline Gadl & $\begin{array}{l}\text { Sense, TTGTGCTTTGCTGTGTTTTAGAGA } \\
\text { Antisense, CCCCCTGCCCAAAGATAGAC }\end{array}$ \\
\hline Slc32al & $\begin{array}{l}\text { Sense, TCACGACAAACCCAAGATCAC } \\
\text { Antisense, GTCTTCGTTCTCCTCGTACAG }\end{array}$ \\
\hline Calb2 & $\begin{array}{l}\text { Sense, TGAGAATGAACTGGACGCCCTC } \\
\text { Antisense, GTAGAGCTTCCCTGCCTCGG }\end{array}$ \\
\hline
\end{tabular}




\begin{tabular}{|c|c|}
\hline Pvalb & $\begin{array}{l}\text { Sense, TCGATGACAGACGTGCTCAG } \\
\text { Antisense, CTTCACCTCATCCGGGTTCT }\end{array}$ \\
\hline Calb1 & $\begin{array}{l}\text { Sense, AGGAAAGGAGCTGCAGAACT } \\
\text { Antisense, CTCTCTGTCCATATTGATCCACA }\end{array}$ \\
\hline Calb2 & $\begin{array}{l}\text { Sense, TGAGAATGAACTGGACGCCCTC } \\
\text { Antisense, GTAGAGCTTCCCTGCCTCGG }\end{array}$ \\
\hline Grial & $\begin{array}{l}\text { Sense, CGAGTTCTGCTACAAATCCCG } \\
\text { Antisense, ACСАCTCTGCCATTCTCTCC }\end{array}$ \\
\hline Gria2 & $\begin{array}{l}\text { Sense, AGGCGAAACGAATGAAGGTG } \\
\text { Antisense, CTTGCCTTGTTCCTCGTGG }\end{array}$ \\
\hline Grm 1 & $\begin{array}{l}\text { Sense, TGCCGCTCCAACACCTTCCT } \\
\text { Antisense, CACATGCTGTCCCTTGGGCG }\end{array}$ \\
\hline Serpin9 & $\begin{array}{l}\text { Sense, CCATCTCTGCTTCCTACAACCTGGA } \\
\text { Antisense, CTATAAGTTTGGTGGTGGTGGCTGC }\end{array}$ \\
\hline Agtr 2 & $\begin{array}{l}\text { Sense, CCCCTTGTTTGGTGTATGGCTTGTC } \\
\text { Antisense, GAGCATATTTCTCGGGTGGGAAAGC }\end{array}$ \\
\hline Ntsr 1 & $\begin{array}{l}\text { Sense, GGCGCCTCATGTTCTGCTATATCTC } \\
\text { Antisense, TGATGGCTGAGCTGACGTAGAAGAG }\end{array}$ \\
\hline Acan & $\begin{array}{l}\text { Sense, CTCGGGCAGAAGAAAGATCGCTAC } \\
\text { Antisense, GGTCTCATGCTCCGCTTCTGTAG }\end{array}$ \\
\hline Grp & $\begin{array}{l}\text { Sense, GCACGGTCCTGGCTAAGATGTA } \\
\text { Antisense, GCATACAGGGACGGGGATTCAT }\end{array}$ \\
\hline Tbp $2 a$ & $\begin{array}{l}\text { Sense, ATCGAGTCCGGTAGCCGGTG } \\
\text { Antisense, GAAACCTAGCCAAACCGCC }\end{array}$ \\
\hline
\end{tabular}

\section{Cell Sorting}

The brains of $D r d 2+/+$ and $D r d 2 f / f$ mice injected with AAV8-Cmv-Cre-eGFP viral vectors were used to purify PCs based on enhanced green fluorescent protein (eGFP) expression as previously described ${ }^{79}$. The brains were dissected in frozen ACSF containing $20 \mathrm{mM}$ glucose 
and $2 \mathrm{mM} \mathrm{Cacl} 2$, then cut in $350-\mu \mathrm{m}$ sections with a chopper. Slices were separated under the microscope and incubated with oxygenation in ACSF containing $20 \mathrm{mM}$ glucose, $2 \mathrm{mM} \mathrm{Cacl} 2$, $0.1 \mu \mathrm{M}$ TTX, $0.05 \mathrm{mM}$ APV, and $0.02 \mathrm{mM}$ DNQX for $1 \mathrm{~h}$. Slices were transferred in ACSF/glucose/Cacl2/pronase (Sigma, P5147). The slices were incubated in $0.5 \mathrm{mg} / \mathrm{ml}$ of pronase during $40 \mathrm{~min}$. After an hour of new ACSF/glucose/Cacl2/TTX/APV/DNQX incubation, slices were transferred to an $\mathrm{ACSF} / \mathrm{glucose} / \mathrm{Cacl} 2 / 1 \% \mathrm{SVF}$ medium. Two lobules infected by the viral vectors were micro-dissected, enzymatically and mechanically dissociated, and plated on a 100-mm Sylgard-bottom Petri dish. After the cells settled, fluorescent neurons were aspirated into a micropipette broken to a diameter of 30 to $50 \mu \mathrm{m}$. Then, the cells were transferred into a new Sylgard-bottom dish, and the same procedure was applied three times to obtain near full purity of the fluorescent cells. After the third round of purification, around 4050 cells were transferred into a glassbottom dish in a small drop ( 1 to $5 \mu$ l) where they could be better inspected for purity under a fluorescence compound microscope. Pure samples were transferred in a $500 \mu 1$-eppendorff tube and immediately lysed for RNA extraction using the RNeasy Microkit (Qiagen; Cat\#74004) following manufacturer's instructions. cDNA Synthesis and qRT-PCR were performed as previously described.

\section{Single Molecule Fluorescent In Situ Hybridization RNAscope}

For the examination of targeted RNA within intact cells, in situ hybridization RNAscope technology was used following the protocol described by the supplier. Mice were decapitated and brain extracted. Tissue was frozen immediately on dry ice and stored at $-80^{\circ} \mathrm{C}$. Brains were sectioned at $-17^{\circ} \mathrm{C}$ with the cryostat at $14 \mu \mathrm{m}$ and mounted onto Superfrost Utra Plus slides (Thermo Scientific; Cat\# J4800AMNZ). Sections of brain were collected for the whole cerebellum from bregma $-5.80 \mathrm{~mm}$ and $-6.80 \mathrm{~mm}$. Probes for Drd2 (ACDBio; Cat\# 406501C3) and Slc32al (ACDBio; Cat\#319191-C2) were used with the RNAscope Fluorescent 
bioRxiv preprint doi: https://doi.org/10.1101/2019.12.20.884288; this version posted December 21, 2019. The copyright holder for this preprint (which was not certified by peer review) is the author/funder, who has granted bioRxiv a license to display the preprint in perpetuity. It is made available under aCC-BY-NC-ND 4.0 International license.

Multiplex Kit (ACDBio; Cat\# 320850) as described by the supplier. Slides were counterstained for DAPI and mounted with ProLong Diamond Antifade mountant (Invitrogen; Cat\# P36961).

\section{iDISCO}

iDISCO methodology was performed in a cerebellum of RiboTag::Drd2-Cre mouse following the protocol previously described ${ }^{33,80}$. Primary antibody anti-HA (Biolegend, Cat $\# 901502$, RRID:AB_2565007) and secondary antibody goat Alexa Fluor 488-coupled anti-mouse (1:500, Thermo Fisher Cat\#A-11001, RRID:AB_2534069) were used. 3D imaging acquisition was performed by using an ultramicroscope I (LaVision BioTec) with the ImspectorPro software (LaVision BioTec) and movies were generated using Imaris x64 software (version 8.0.1, Bitplane).

\section{Whole-cell patch-clamp electrophysiological recordings}

Unless indicated, all chemicals were from Hello Bio (Bristol, UK). Experiments were performed in parasagittal vermis cerebellar slices, which were prepared in $\sim 2$ months old mice as described previously. Artificial CSF (ACSF) contained the following (in mm): $126 \mathrm{NaCl}, 3$ $\mathrm{KCl}, 1.25 \mathrm{NaH} 2 \mathrm{PO} 4,1.3 \mathrm{MgSO} 4,26 \mathrm{NaHCO} 3,2.5 \mathrm{CaCl}$, and 10 glucose equilibrated with $95 \% \mathrm{O} 2$ plus $5 \% \mathrm{CO} 2$. After a recovery time of $\geq 80 \mathrm{~min}$, slices were transferred to a chamber perfused with ACSF containing $100 \mu \mathrm{m}$ picrotoxin at a rate of $2-3 \mathrm{ml} / \mathrm{min}$. When indicated, quinpirole hydrochloride (Trocris Bioscience; Cat \#1061) was added to the ACSF at final 10 $\mu \mathrm{M}$ concentration. Whole-cell patch-clamp electrophysiological recordings were performed under infrared-differential interference contrast microscopy at $31-32^{\circ} \mathrm{C}$ with Multiclamp $700 \mathrm{~B}$ amplifiers (Molecular Devices, Sunnyvale, CA). The location of the stimulating electrode was gently adjusted around the dendritic tree of the patched cell. Patch pipettes had resistances of 3-5 M $\Omega$. Access resistances were between 20 and $35 \mathrm{M} \Omega$; if access resistance changed $>20 \%$, 
the recording was discarded. Whole-cell voltage-clamp recordings of AMPAR-mediated EPSCs were performed at a holding potential between -60 and $-50 \mathrm{mV}$ using an internal solution containing the following (in $\mathrm{mM}$ ): $60 \mathrm{CsCl}, 30 \mathrm{Cs}$ d-gluconate, 20 tetraethylammonium-Cl, 20 EGTA, $4 \mathrm{MgCl} 2,4 \mathrm{ATP}$, and $30 \mathrm{HEPES}, \mathrm{pH}$ 7.3, adjusted with $\mathrm{CsOH}$. Paired-pulse experiments were performed at an interpulse interval of $50 \mathrm{~ms}$; the pairedpulse ratio (PPR) was calculated as the ratio between the second and first EPSCs.

\section{Behavioral Assays}

Male RiboTag::Drd2f/f, RiboTag::Drd2+/+, Drd2-f/f and Drd2-+/+ mice were injected with AAV8-Cmv-Cre-eGFP and AAVDJ-Pcp2-Cre viruses. Similarly, wild type C57Bl/6j mice were injected with AAV8-Cmv-eGFP and AAV8-Cmv-m-Drd2-IRES-eGFP. Behavioral evaluation was performed 21 days after surgery. Mice were handled for 3 days prior to testing for habituation. All experiments were blinded to genotype during behavioral testing.

\section{Locomotor Activity}

Horizontal and vertical activity was measured in a circular corridor (Imetronic, Pessac, France) for $60 \mathrm{~min}$. Counts for horizontal activity were incremented by consecutive interruption of two adjacent beams placed at a height of $1 \mathrm{~cm}$ per $90^{\circ}$ sector of the corridor (mice moving through $1 / 4$ of the circular corridor) and counts for vertical activity (rearings) corresponding to interruption of beams placed at a height of $7.5 \mathrm{~cm}$ along the corridor (mice stretching upwards) were used as a measure for exploratory activity. The circular corridor was cleaned with $70 \%$ ethanol and dried between each test.

\section{Accelerating Rotarod}

Accelerating rotarod was used to measure the cerebellar learning as it was previously described $^{81}$. For 2 consecutive days, the mice were trained to hold onto the rod at a constant speed $(4 \mathrm{rpm})$ for at least 60 seconds. On the test day, the rod accelerated from 4 to $40 \mathrm{rpm}$ 
within 5 minutes and the speed and the latency to fall were recorded over 10 consecutive trials. Data is expressed as: (Latency to fall on trial $10^{\text {th }}$ - Latency to fall on trial $1^{\text {st }}$ ) and (Speed on trial $10^{\text {th }}-$ Speed on trial $\left.1^{\text {st }}\right)$.

\section{Coat-hanger test}

We used a coat hanger (diameter: $2 \mathrm{~mm}$, length: $40 \mathrm{~cm}$ ) divided into 12 segments (length: 5 $\mathrm{cm}$ ) and suspended at $40 \mathrm{~cm}$ from cushioned surface to evaluate the fine motor coordination as it was previously described ${ }^{81}$. Mice were placed in the middle of the hanger, and the fall latency and the number of movements were evaluated for a total of 60 seconds. The test finishes when the animal fells down or when the 60 seconds elapsed.

\section{Beam-walking test}

Beam-walking test was performed to evaluate the fine motor coordination as it was previously described $^{82}$. Mice were trained to cross a horizontal wooden circle rod $(1 \mathrm{~m} \mathrm{long}, 3 \mathrm{~cm}$ in diameter) placed $60 \mathrm{~cm}$ above a cushioned table for 2 days before the test. The day of the test, mice crossed twice a wide wooden rod $(3 \mathrm{~cm}$ in diameter) and a narrow wooden rod $(1 \mathrm{~cm}$ in diameter). The total number of footslips was recorded in each mouse and used to calculate the mean for each experimental group.

\section{Three-Chamber Social Approach}

A three-chamber arena was used to assess sociability and preference for social novelty similarly as it was previously published ${ }^{83}$. The rectangular arena $(60 \times 40 \times 22 \mathrm{~cm})$ is divided by Plexiglas walls with openings of $8 \mathrm{~cm}$ in diameter allowing the access into each chamber $(20 \times 40 \times 22$ $\mathrm{cm})$. The middle chamber was used to place the evaluated mouse at the beginning of each trial. The two side chambers contained an empty squared wire cage $(8 \times 10 \mathrm{~cm})$ in which the social (strangers) or the non-social (object) stimuli could be enclosed. Wire cages present small holes allowing the visual, auditory, olfactory and tactile contact of tested mice with the stimuli confined inside the cages. A weighted cup was placed on the top of the wire cages to prevent 
the tested mice to climb.

The three-chamber test consisted in three phases of $10 \mathrm{~min}$. In the first phase (Habituation), the evaluated mouse was placed in the middle chamber and allowed to freely explore the three chamber compartments for a period of 10 minutes. During the second phase (Sociability), an unfamiliar juvenile mouse (Stranger1) (from the same mouse line and same gender) that had no prior contact with the tested mouse, was placed in one of the wire cages. In the opposite side chamber, the nonsocial stimuli (Object) was equally enclosed and the evaluated mouse was allowed to freely explore the three chambers for $10 \mathrm{~min}$. During the third face of the test (Preference for Social Novelty), the nonsocial stimuli (Object) was replaced by a new unfamiliar mouse (Stranger 2). The tested mouse was then given the possibility to interact with both stranger 1 and stranger 2 for $10 \mathrm{~min}$. Mice used as social stimuli (Strangers) were habituated to the wire cage for a brief period of time for 3 days before the start of the experiment. Every session was video-tracked and the number of entries that the tested mouse performed in each chamber, the total time it spent in each compartment and in interaction with the object and strangers were manually scored by an experimenter blind to the genotype of the animals. Mice were considered to be exploring the Object and the Strangers when their nose was directed toward the cage at a distance less than approximately $1 \mathrm{~cm}$ or directly interacting with the wire cages enclosing stimuli. The arena was cleaned with $70 \%$ of ethanol and dried during few minutes between trials.

\section{Statistical analyses}

GraphPad Prism v6.0 software was used for statistical analyses. For normally distributed parameters, Student's t test was used. Multiple comparisons were performed by one-way and two-way ANOVA or two-way repeated measures ANOVA followed by a post-hoc analysis. All data are presented as mean \pm SEM, and statistical significance was accepted at $5 \%$ level. 
bioRxiv preprint doi: https://doi.org/10.1101/2019.12.20.884288; this version posted December $21,2019$. The copyright holder for this preprint (which was not certified by peer review) is the author/funder, who has granted bioRxiv a license to display the preprint in perpetuity. It is made available under aCC-BY-NC-ND 4.0 International license.

${ }^{*} \mathrm{p}<0.05,{ }^{*} \mathrm{p}<0.01, * * * \mathrm{p}<0.001$. For more detailed information about the statistics, check the document "Statistical report by figures". 


\section{Acknowledgments}

We thank Dr. Endo Shogo and Dr. Philippe Isoppe for providing us antibodies against Gsubstrate and Zebrin-II. This work was supported by Inserm, Fondation pour la Recherche Médicale (DEQ20160334919), La Marató de TV3 Fundació, ANR EPITRACES (EV), ANR DOPAFEAR (EV) and NARSAD Young Investigator Grant from the Brain and Behavior Research Foundation (EP). LC is supported by the post-doctoral Labex EpiGenMed fellowship («Investissements d'avenir» ANR-10-LABX-12-01), EP was a recipient of Marie Curie IntraEuropean Fellowship IEF327648 and is currently a recipient of Beatriu de Pinós fellowship (\# 2017BP00132) from University and Research Grants Management Agency (Government of Catalonia). LC is supported by the pre-doctoral Labex EpiGenMed («Investissements d'avenir» ANR-10-LABX-12-01).

\section{Author contribution}

L.C, E.P and E.V conceived and led the project. L.C, E.P and E.V designed the study. L.C, E.P and E.V conceptualized the project. L.C and E.P performed brain dissections. L.C and E.P performed polysome IP and qRT-PCR experiments. L.C performed western blot analyses. L.C, E.P and P.T performed immunofluorescence assessments. L.C and L.C performed in situ hybridization analysis. L.C performed stereotaxic injections and behavioral experiments. L.C, M.B and A.C performed iDISCO methodology. L.C and F.B performed in vivo cerebellar slices. L.C and M.A-L designed AAVDJ-Pcp2-Cre, L.C and F.A performed PCs-sorting, M.R provided D2R-floxed mice. M.M performed electrophysiological analyses. E.V supervised the project. L.C and E.V wrote the manuscript with input from all authors. The authors declare no conflicts of interest. 


\section{References}

1. Ito, M. Mechanisms of motor learning in the cerebellum. Brain Research vol. 886 (2000).

2. Medina, J. F., Nores, W. L., Ohyama, T. \& Mauk, M. D. Mechanisms of cerebellar learning suggested by eyelid conditioning. Curr. Opin. Neurobiol. 10, 717-724 (2000).

3. Schmahmann, J. D. \& Caplan, D. Cognition, emotion and the cerebellum. Brain 129, 290-292 (2006).

4. Schmahmann, J. D. The cerebellum and cognition. Neuroscience Letters vol. 688 6275 (2019).

5. Locke, T. M. et al. Dopamine D1 Receptor-Positive Neurons in the Lateral Nucleus of the Cerebellum Contribute to Cognitive Behavior. Biol. Psychiatry 84, 401-412 (2018).

6. Carta, I., Chen, C. H., Schott, A. L., Dorizan, S. \& Khodakhah, K. Cerebellar modulation of the reward circuitry and social behavior. Science (80-. ). 363, (2019).

7. Ruigrok, T. J. H. Ins and outs of cerebellar modules. Cerebellum 10, 464-474 (2011).

8. Mostofi, A., Holtzman, T., Grout, A. S., Yeo, C. H. \& Edgley, S. A. Electrophysiological localization of eyeblink-related microzones in rabbit cerebellar cortex. J. Neurosci. 30, 8920-8934 (2010).

9. Ashida, R., Cerminara, N. L., Brooks, J. \& Apps, R. Principles of organization of the human cerebellum: macro- and microanatomy. in Handbook of Clinical Neurology vol. 154 45-58 (Elsevier B.V., 2018).

10. Nelson, T. E., King, J. S. \& Bishop, G. A. Distribution of tyrosine hydroxylaseimmunoreactive afferents to the cerebellum differs between species. J. Comp. Neurol. 379, 443-454 (1997).

11. Panagopoulos, N. T., Papadopoulos, G. C. \& Matsokis, N. A. Dopaminergic innervation and binding in the rat cerebellum. Neurosci. Lett. 130, 208-212 (1991).

12. Ikai, Y., Takada, M. \& Mizuno, N. Single neurons in the ventral tegmental area that project to both the cerebral and cerebellar cortical areas by way of axon collaterals. Neuroscience 61, 925-34 (1994). 
13. Ikai, Y., Takada, M., Shinonaga, Y. \& Mizuno, N. Dopaminergic and nondopaminergic neurons in the ventral tegmental area of the rat project, respectively, to the cerebellar cortex and deep cerebellar nuclei. Neuroscience 51, 719-28 (1992).

14. Kizer, J. S., Palkovits, M. \& Brownstein, M. J. The projections of the A8, A9 and A10 dopaminergic cell bodies: evidence for a nigral-hypothalamic-median eminence dopaminergic pathway. Brain Res. 108, 363-370 (1976).

15. Barili, P., Bronzetti, E., Ricci, A., Zaccheo, D. \& Amenta, F. Microanatomical localization of dopamine receptor protein immunoreactivity in the rat cerebellar cortex. Brain Res. 854, 130-138 (2000).

16. Boyson, S. J., McGonigle, P. \& Molinoff, P. B. Quantitative autoradiographic localization of the D1 and D2 subtypes of dopamine receptors in rat brain. J. Neurosci. 6, 3177-3188 (1986).

17. Bouthenet, M. L., Martres, M. P., Sales, N. \& Schwartz, J. C. A detailed mapping of dopamine D-2 receptors in rat central nervous system by autoradiography with [125I]iodosulpride. Neuroscience 20, 117-55 (1987).

18. Mengod, G., Martinez-Mir, M. I., Vilaro, M. T. \& Palacios, J. M. Localization of the mRNA for the dopamine D2 receptor in the rat brain by in situ hybridization histochemistry. Proc. Natl. Acad. Sci. U. S. A. 86, 8560-8564 (1989).

19. Camps, M., Kelly, P. H. \& Palacios, J. M. Autoradiographic localization of dopamine D1 and D2 receptors in the brain of several mammalian species. J. Neural Transm. 80, 105-127 (1990).

20. Eisenstein, S. A. et al. Characterization of extrastriatal D2 in vivo specific binding of [18F](N-methyl)benperidol using PET. Synapse 66, 770-780 (2012).

21. Matuskey, D. et al. Age-related changes in binding of the D2/3 receptor radioligand [11C](+)PHNO in healthy volunteers. Neuroimage 130, 241-247 (2016).

22. Courchesne, E., Yeung-Courchesne, R., Hesselink, J. R. \& Jernigan, T. L. Hypoplasia of Cerebellar Vermal Lobules VI and VII in Autism. N. Engl. J. Med. 318, 1349-1354 (1988).

23. D’Mello, A. M. \& Stoodley, C. J. Cerebro-cerebellar circuits in autism spectrum disorder. Front. Neurosci. 9, (2015). 
24. Murakami, J. W., Courchesne, E., Press, G. A., Yeung-Courchesne, R. \& Hesselink, J. R. Reduced cerebellar hemisphere size and its relationship to vermal hypoplasia in autism. Arch. Neurol. 46, 689-94 (1989).

25. Wassink, T. H., Andreasen, N. C., Nopoulos, P. \& Flaum, M. Cerebellar morphology as a predictor of symptom and psychosocial outcome in schizophrenia. Biol. Psychiatry 45, 41-8 (1999).

26. Baldaçara, L., Borgio, J. G. F., De Lacerda, A. L. T. \& Jackowski, A. P. Cerebellum and psychiatric disorders. Revista Brasileira de Psiquiatria vol. 30 281-289 (2008).

27. Andreasen, N. C. \& Pierson, R. The Role of the Cerebellum in Schizophrenia. Biological Psychiatry vol. 64 81-88 (2008).

28. Webb, S. J. et al. Cerebellar vermal volumes and behavioral correlates in children with autism spectrum disorder. Psychiatry Res. - Neuroimaging 172, 61-67 (2009).

29. Baldaçara, L. et al. Is cerebellar volume related to bipolar disorder? J. Affect. Disord. 135, 305-309 (2011).

30. Watson, D. R. et al. A voxel based morphometry study investigating brain structural changes in first episode psychosis. Behav. Brain Res. 227, 91-99 (2012).

31. Shakiba, A. The role of the cerebellum in neurobiology of psychiatric disorders. Neurol. Clin. 32, 1105-15 (2014).

32. Puighermanal, E. et al. Drd2-cre: Ribotag mouse line unravels the possible diversity of dopamine $\mathrm{d} 2$ receptor-expressing cells of the dorsal mouse hippocampus. Hippocampus 25, 858-875 (2015).

33. Renier, N. et al. IDISCO: A simple, rapid method to immunolabel large tissue samples for volume imaging. Cell 159, 896-910 (2014).

34. Puighermanal, E. et al. Anatomical and molecular characterization of dopamine D1 receptor-expressing neurons of the mouse CA1 dorsal hippocampus. Brain Struct. Funct. 222, 1897-1911 (2017).

35. Gall, D. et al. Altered Neuronal Excitability in Cerebellar Granule Cells of Mice Lacking Calretinin. J. Neurosci. 23, 9320-9327 (2003). 
36. Schilling, K. \& Oberdick, J. The treasury of the commons: Making use of public gene expression resources to better characterize the molecular diversity of inhibitory interneurons in the cerebellar cortex. Cerebellum 8, 477-489 (2009).

37. Dal Toso, R. et al. The dopamine D2 receptor: two molecular forms generated by alternative splicing. EMBO J. 8, 4025-34 (1989).

38. Montmayeur, J. P. et al. Differential expression of the mouse D2 dopamine receptor isoforms. FEBS Lett. 278, 239-43 (1991).

39. De Mei, C., Ramos, M., Iitaka, C. \& Borrelli, E. Getting specialized: presynaptic and postsynaptic dopamine D2 receptors. Curr. Opin. Pharmacol. 9, 53-8 (2009).

40. Surmeier, D. J., Ding, J., Day, M., Wang, Z. \& Shen, W. D1 and D2 dopaminereceptor modulation of striatal glutamatergic signaling in striatal medium spiny neurons. Trends in Neurosciences vol. 30 228-235 (2007).

41. Chung, H. J., Steinberg, J. P., Huganir, R. L. \& Linden, D. J. Requirement of AMPA receptor GluR2 phosphorylation for cerebellar long-term depression. Science 300, 1751-5 (2003).

42. Steinberg, J. P. et al. Targeted in vivo mutations of the AMPA receptor subunit GluR2 and its interacting protein PICK1 eliminate cerebellar long-term depression. Neuron 49, 845-860 (2006).

43. Broekman, M. L. D., Comer, L. A., Hyman, B. T. \& Sena-Esteves, M. Adenoassociated virus vectors serotyped with AAV8 capsid are more efficient than AAV-1 or -2 serotypes for widespread gene delivery to the neonatal mouse brain. Neuroscience 138, 501-510 (2006).

44. Yang, M., Silverman, J. L. \& Crawley, J. N. Automated three-chambered social approach task for mice. Curr. Protoc. Neurosci. Chapter 8, Unit 8.26 (2011).

45. de Leeuw, C. N. et al. rAAV-compatible MiniPromoters for restricted expression in the brain and eye. Mol. Brain 9, 52 (2016).

46. Martres, M. P., Sales, N., Bouthenet, M. L. \& Schwartz, J. C. Localisation and pharmacological characterisation of D-2 dopamine receptors in rat cerebral neocortex and cerebellum using [125I]iodosulpride. Eur. J. Pharmacol. 118, 211-9 (1985). 
47. Martres, M. P., Bouthenet, M. L., Sales, N., Sokoloff, P. \& Schwartz, J. C. Widespread distribution of brain dopamine receptors evidenced with [125I]iodosulpride, a highly selective ligand. Science 228, 752-5 (1985).

48. Gehlert, D. R. \& Wamsley, J. K. Dopamine receptors in the rat brain: quantitative autoradiographic localization using [3H] sulpiride. Neurochem. Int. 7, 717-723 (1985).

49. Mansour, A. et al. Localization of dopamine D2 receptor mRNA and D1 and D2 receptor binding in the rat brain and pituitary: An in situ hybridization-receptor autoradiographic analysis. J. Neurosci. 10, 2587-2600 (1990).

50. Meador-Woodruff, J. H. et al. Distribution of D2 dopamine receptor mRNA in rat brain. Proc. Natl. Acad. Sci. U. S. A. 86, 7625-7628 (1989).

51. Bouthenet, M. L. et al. Localization of dopamine D3 receptor mRNA in the rat brain using in situ hybridization histochemistry: comparison with dopamine D2 receptor mRNA. Brain Res. 564, 203-219 (1991).

52. Levey, A. I. et al. Localization of D1 and D2 dopamine receptors in brain with subtype-specific antibodies. Proc. Natl. Acad. Sci. U. S. A. 90, 8861-8865 (1993).

53. Brock, J. W., Farooqui, S., Ross, K. \& Prasad, C. Localization of dopamine D2 receptor protein in rat brain using polyclonal antibody. Brain Res. 578, 244-50 (1992).

54. Khan, Z. U. et al. Differential regional and cellular distribution of dopamine D2-like receptors: an immunocytochemical study of subtype-specific antibodies in rat and human brain. J. Comp. Neurol. 402, 353-71 (1998).

55. Yu, S. K., Jung, H. S., Hall, F. S. \& Linden, D. J. Dopamine signaling is required for depolarization-induced slow current in cerebellar Purkinje cells. J. Neurosci. 29, 85308538 (2009).

56. Kelly, M. A. et al. Locomotor activity in D2 dopamine receptor-deficient mice is determined by gene dosage, genetic background, and developmental adaptations. $J$. Neurosci. 18, 3470-3479 (1998).

57. Radl, D. et al. Differential regulation of striatal motor behavior and related cellular responses by dopamine d 21 and d2s isoforms. Proc. Natl. Acad. Sci. U. S. A. 115, 198203 (2018). 
58. Neve, K. A. et al. Normalizing dopamine D2 receptor-mediated responses in D2 null mutant mice by virus-mediated receptor restoration: Comparing D2L and D2S. Neuroscience 248, 479-487 (2013).

59. Bolbecker, A. R. et al. Eyeblink conditioning anomalies in bipolar disorder suggest cerebellar dysfunction. Bipolar Disord. 11, 19-32 (2009).

60. Bolbecker, A. R. et al. Eye-blink conditioning deficits indicate temporal processing abnormalities in schizophrenia. Schizophr. Res. 111, 182-191 (2009).

61. Watson, D. J. G. et al. Selective blockade of dopamine D3 receptors enhances while D2 receptor antagonism impairs social novelty discrimination and novel object recognition in rats: a key role for the prefrontal cortex. Neuropsychopharmacology $\mathbf{3 7}$, 770-86 (2012).

62. Millan, M. J. et al. Selective blockade of dopamine D3 versus D2 receptors enhances frontocortical cholinergic transmission and social memory in rats: A parallel neurochemical and behavioural analysis. J. Neurochem. 100, 1047-1061 (2007).

63. Loiseau, F. \& Millan, M. J. Blockade of dopamine D(3) receptors in frontal cortex, but not in sub-cortical structures, enhances social recognition in rats: similar actions of D(1) receptor agonists, but not of D(2) antagonists. Eur. Neuropsychopharmacol. 19, 23-33 (2009).

64. Gunaydin, L. A. \& Deisseroth, K. Dopaminergic dynamics contributing to social behavior. Cold Spring Harb. Symp. Quant. Biol. 79, 221-227 (2014).

65. Bariselli, S. et al. Role of VTA dopamine neurons and neuroligin 3 in sociability traits related to nonfamiliar conspecific interaction. Nat. Commun. 9, (2018).

66. Fields, H. L., Hjelmstad, G. O., Margolis, E. B. \& Nicola, S. M. Ventral Tegmental Area Neurons in Learned Appetitive Behavior and Positive Reinforcement. Annu. Rev. Neurosci. 30, 289-316 (2007).

67. Bellone, C. et al. Superior Colliculus to VTA pathway controls orienting behavior during conspecific interaction. bioRxiv 735340 (2019) doi:10.1101/735340.

68. Wagner, M. J., Kim, T. H., Savall, J., Schnitzer, M. J. \& Luo, L. Cerebellar granule cells encode the expectation of reward. Nature 544, 96-100 (2017). 
69. Stoodley, C. J. et al. Altered cerebellar connectivity in autism and cerebellar-mediated rescue of autism-related behaviors in mice. Nat. Neurosci. 20, 1744-1751 (2017).

70. Hess, E. J. \& Wilson, M. C. Tottering and leaner mutations perturb transient developmental expression of tyrosine hydroxylase in embryologically distinct Purkinje cells. Neuron 6, 123-32 (1991).

71. Jeong, Y. G., Kim, M. K. \& Hawkes, R. Ectopic expression of tyrosine hydroxylase in zebrin II immunoreactive Purkinje cells in the cerebellum of the ataxic mutant mouse, pogo. Dev. Brain Res. 129, 201-209 (2001).

72. Kempadoo, K. A., Mosharov, E. V., Choi, S. J., Sulzer, D. \& Kandel, E. R. Dopamine release from the locus coeruleus to the dorsal hippocampus promotes spatial learning and memory. Proc. Natl. Acad. Sci. U. S. A. 113, 14835-14840 (2016).

73. Beas, B. S. et al. The locus coeruleus drives disinhibition in the midline thalamus via a dopaminergic mechanism. Nat. Neurosci. 21, 963-973 (2018).

\section{References Materials and Methods}

74. Gong, S. et al. A gene expression atlas of the central nervous system based on bacterial artificial chromosomes. Nature 425, 917-925 (2003).

75. Sanz, E. et al. Cell-type-specific isolation of ribosome-associated mRNA from complex tissues. Proc. Natl. Acad. Sci. U. S. A. 106, 13939-44 (2009).

76. Candelas, M. et al. Cav3.2 T-type calcium channels shape electrical firing in mouse Lamina II neurons. Sci. Rep. 9, (2019).

77. Biever, A. et al. PKA-dependent phosphorylation of ribosomal protein S6 does not correlate with translation efficiency in striatonigral and striatopallidal medium-sized spiny neurons. J. Neurosci. 35, 4113-4130 (2015).

78. Ceolin, L. et al. Cell Type-Specific mRNA Dysregulation in Hippocampal CA1 Pyramidal Neurons of the Fragile X Syndrome Mouse Model. Front. Mol. Neurosci. 10, (2017).

79. Saywell, V., Cioni, J.-M. \& Ango, F. Developmental gene expression profile of axon guidance cues in Purkinje cells during cerebellar circuit formation. Cerebellum 13, 307-17 (2014). 
80. Belle, M. et al. Tridimensional Visualization and Analysis of Early Human Development. Cell 169, 161-173.e12 (2017).

81. Cutando, L. et al. Microglial activation underlies cerebellar deficits produced by repeated cannabis exposure. J. Clin. Invest. 123, 2816-31 (2013).

82. Martínez-Torres, S. et al. Monoacylglycerol lipase blockade impairs fine motor coordination and triggers cerebellar neuroinflammation through cyclooxygenase- 2 . Brain. Behav. Immun. 81, 399-409 (2019).

83. Moy, S. S. et al. Sociability and preference for social novelty in five inbred strains: an approach to assess autistic-like behavior in mice. Genes, Brain Behav. 3, 287-302 (2004). 
bioRxiv preprint doi: https://doi.org/10.1101/2019.12.20.884288; this version posted December 21, 2019. The copyright holder for this

preprint (which was not certified by peer review) is the author/funder, who has granted bioRxiv a license to display the preprint in perpetuity. It is made available under aCC-BY-NC-ND 4.0 International license.

\section{Cutando et al Figure 1}
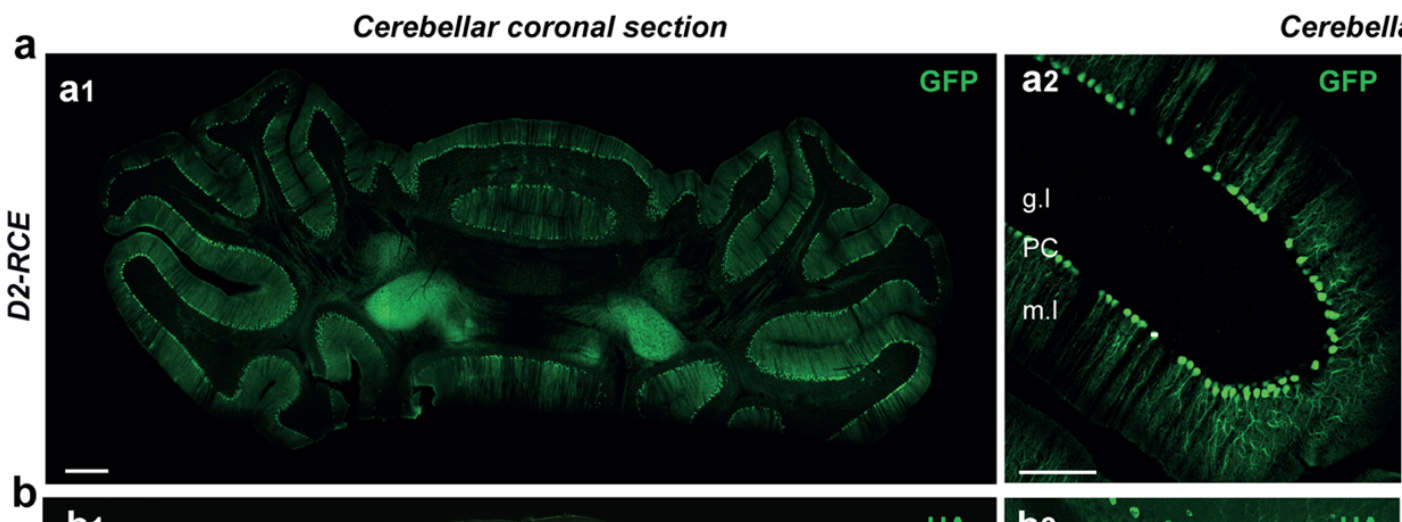

ar cortex
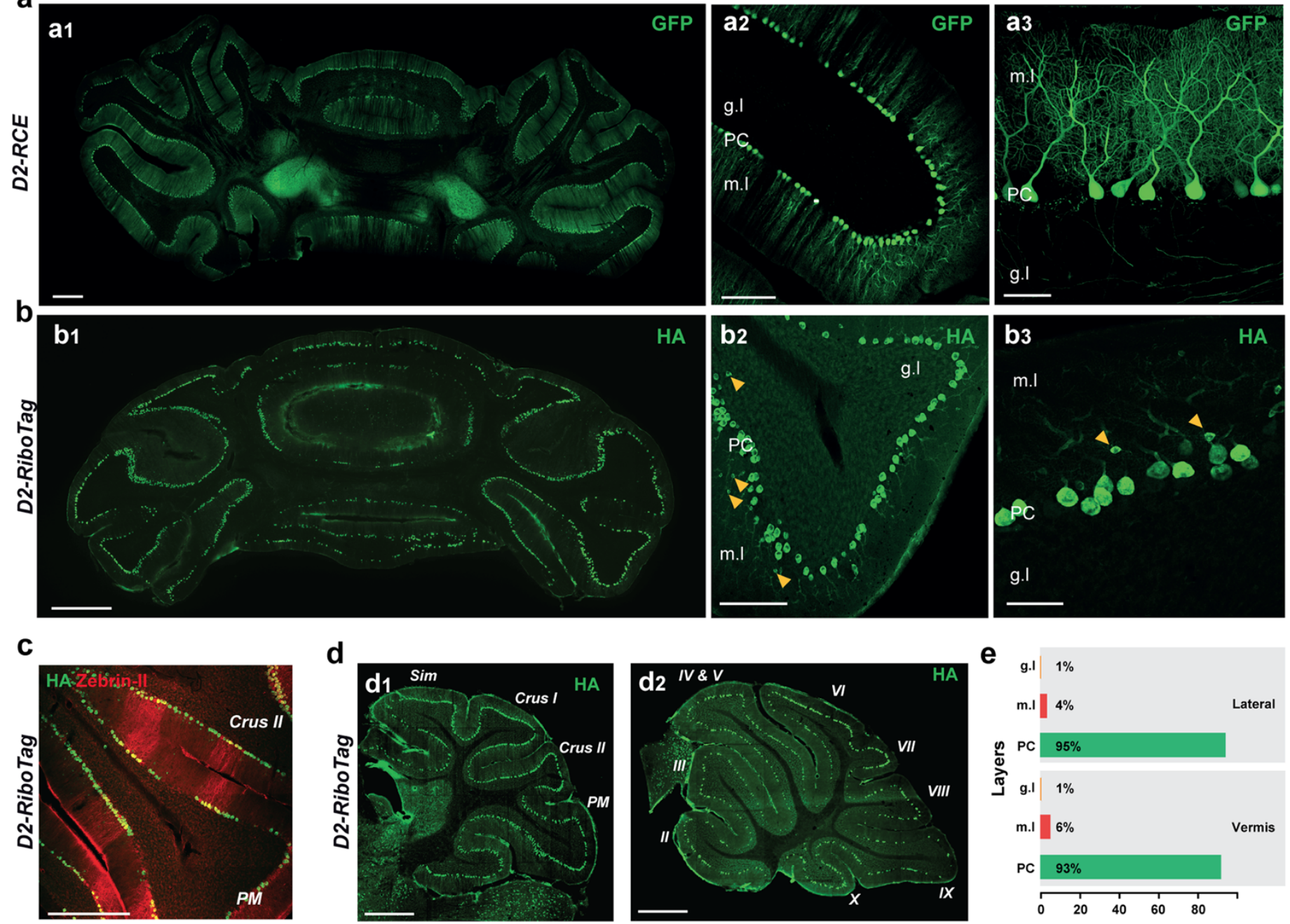

e

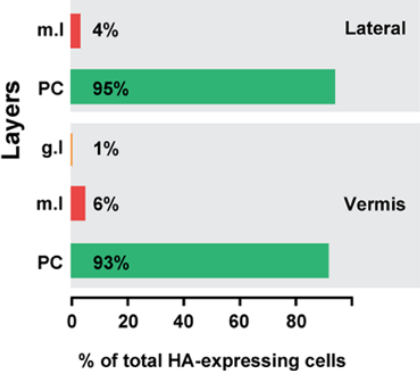




\section{Cutando et al Figure 2}

a

b
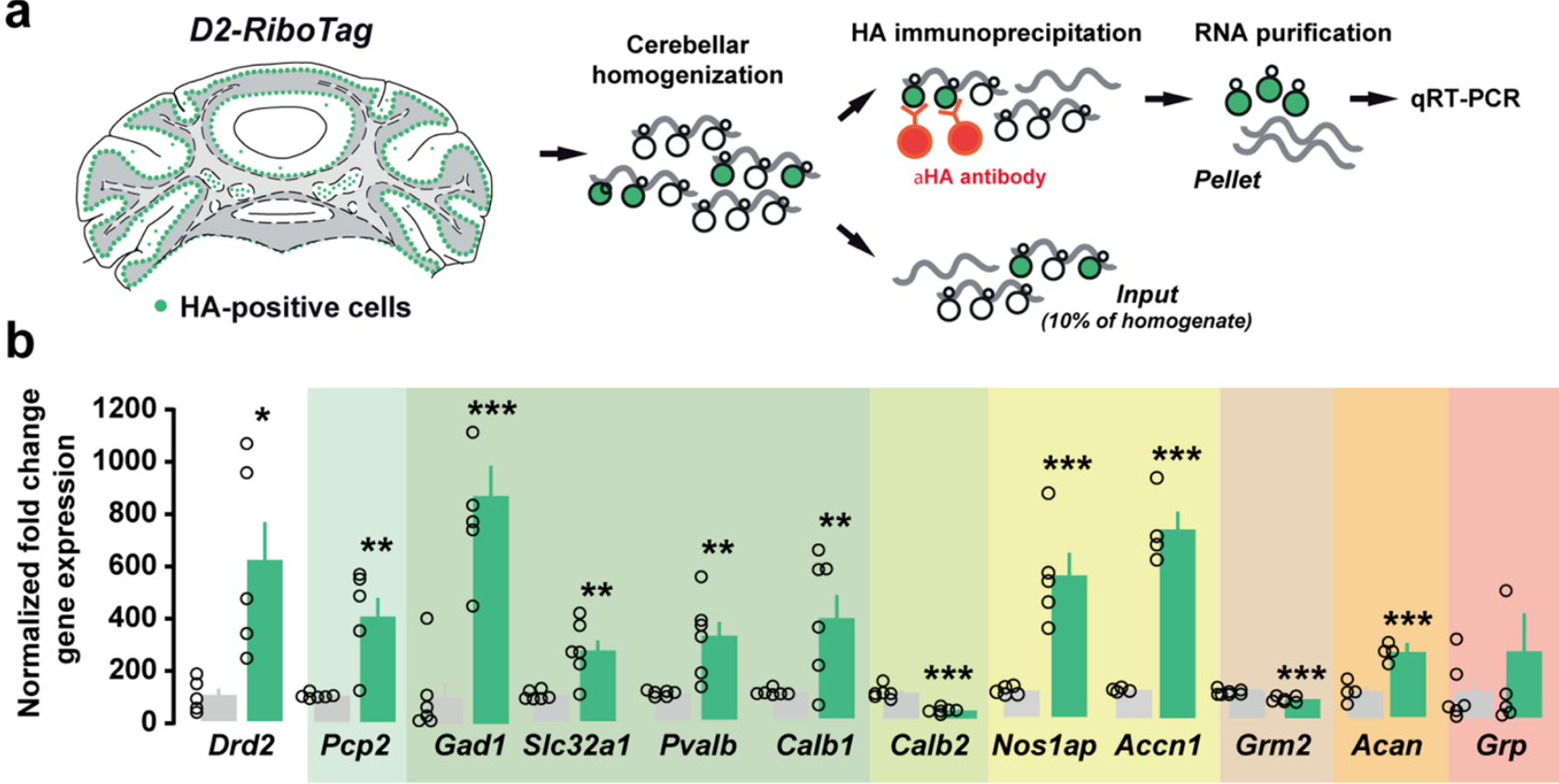

Input

Pellet

C

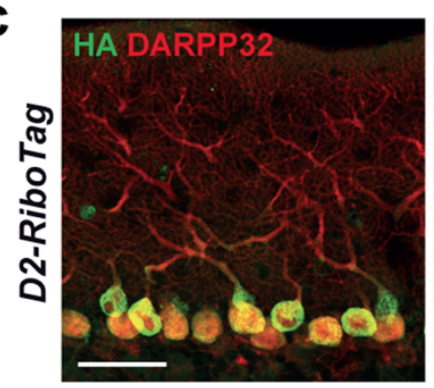

d

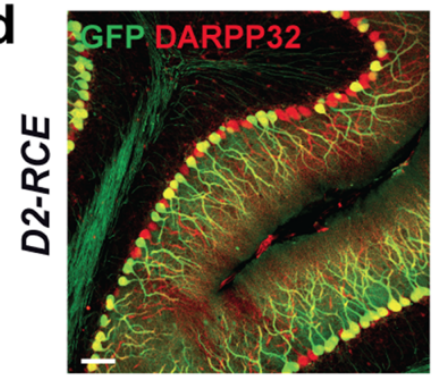

e

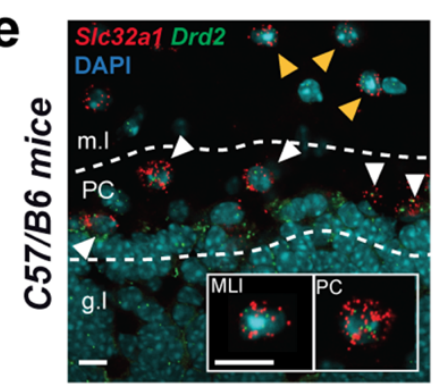

\begin{abstract}
PCs GABAergic IN
\end{abstract}
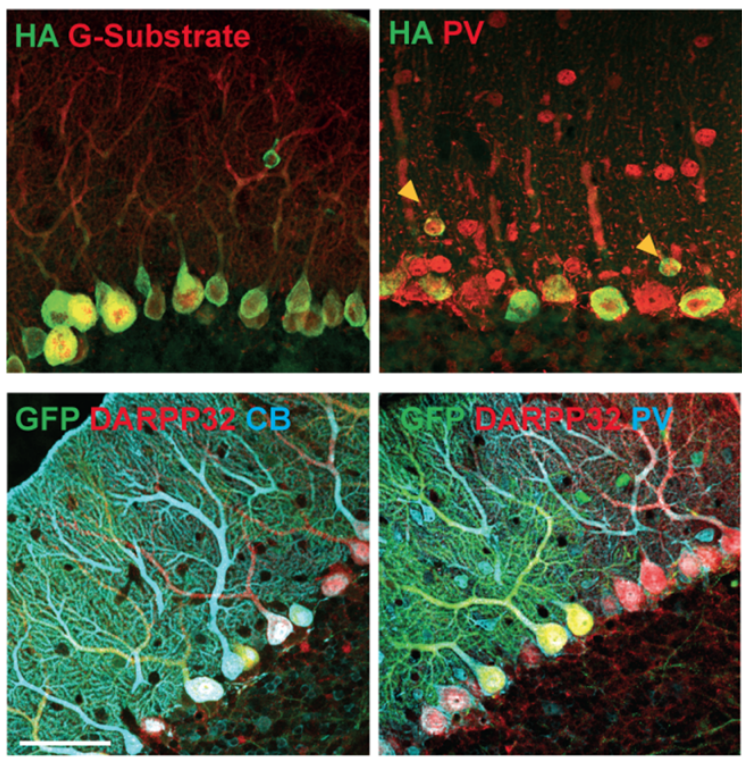

h

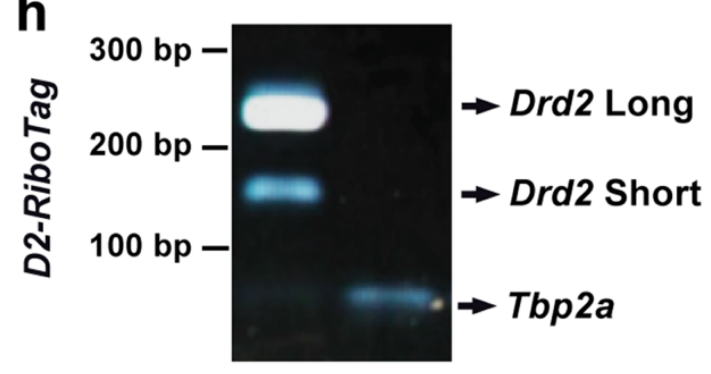

HA immunoprecipitation RNA purification

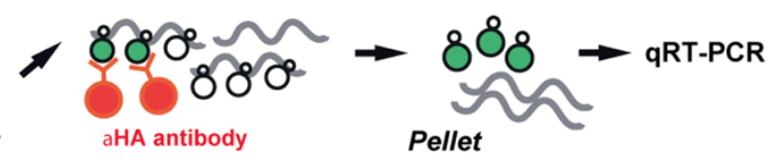

$880^{\circ}$

$880^{\circ}$ Input (10\% of homogenate) 


\section{Cutando et al Figure 3}
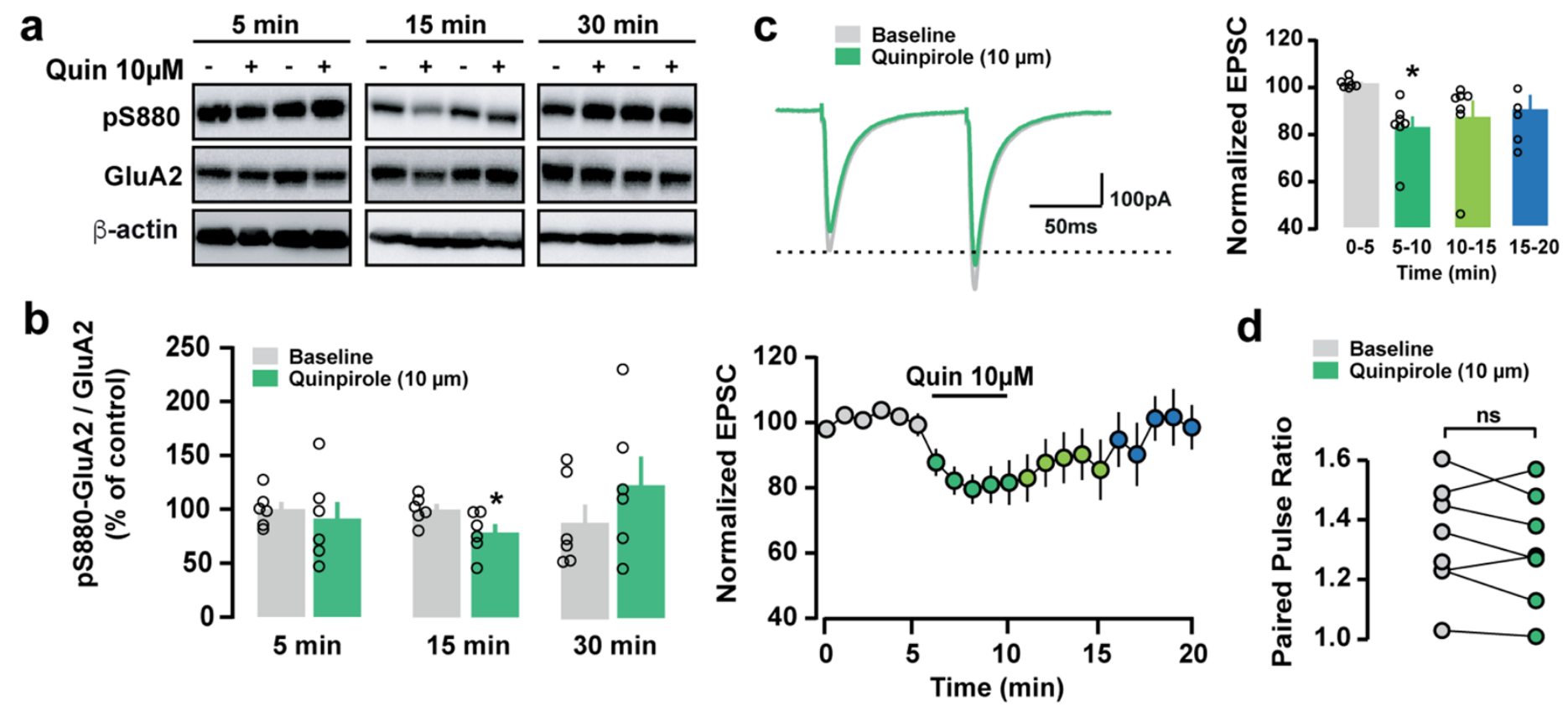

d
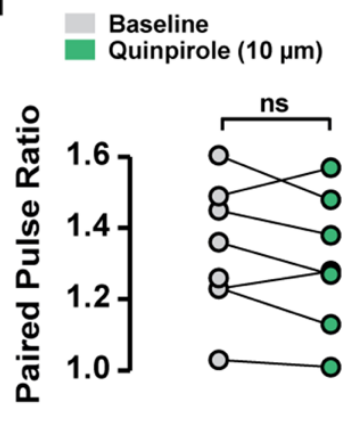


\section{Cutando et al Figure 4}

a

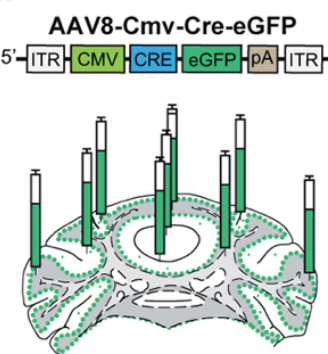

$\operatorname{Drd}^{+/+}$(Control) $\operatorname{Drd2}^{f / f}(P C-D 2 R-C K O)$
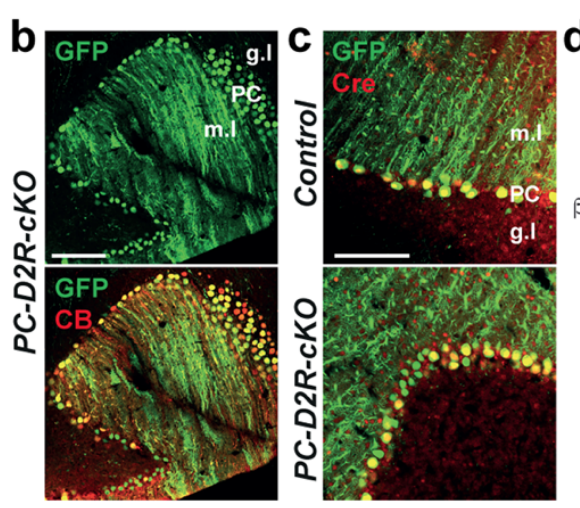
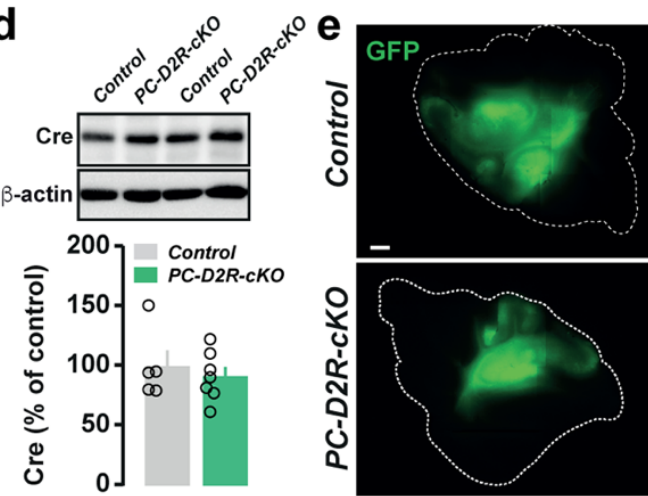

Cell sorting of eGFP-postive neurons

Control

- PC-D2R-cKO

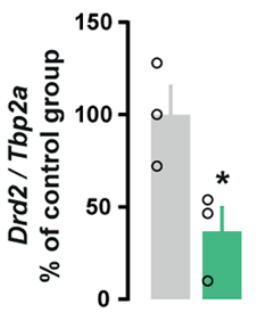

h
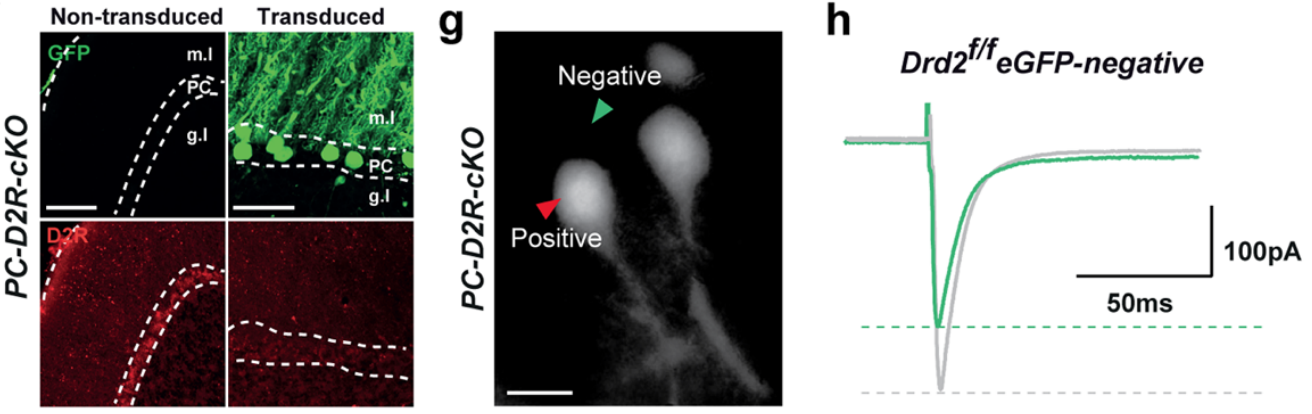

$\operatorname{Drd2}{ }^{f / f}$ eGFP-positive
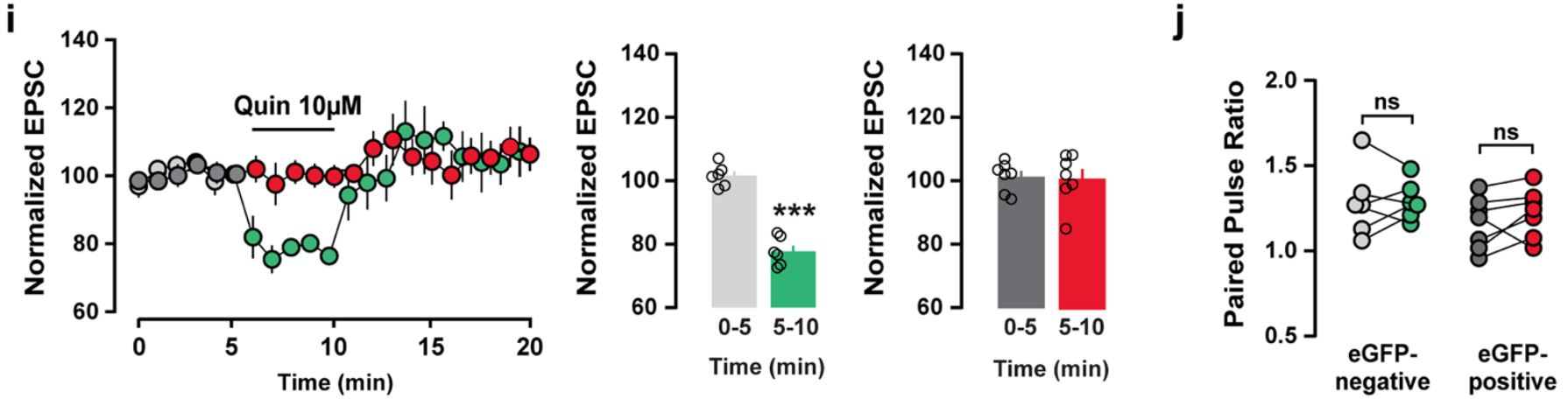


\section{Cutando et al Figure 5}

a

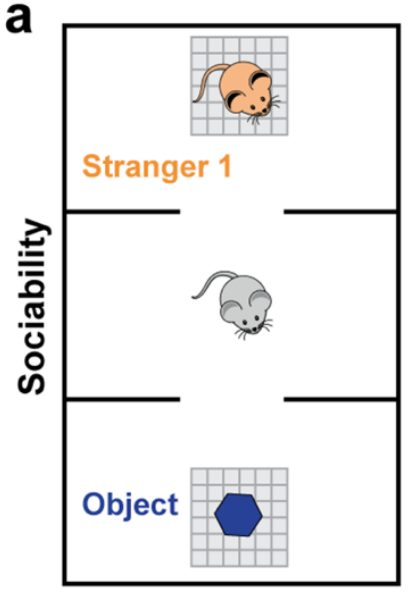

C

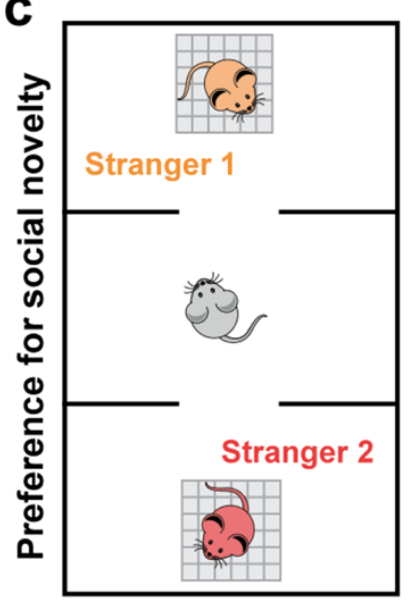

Total time

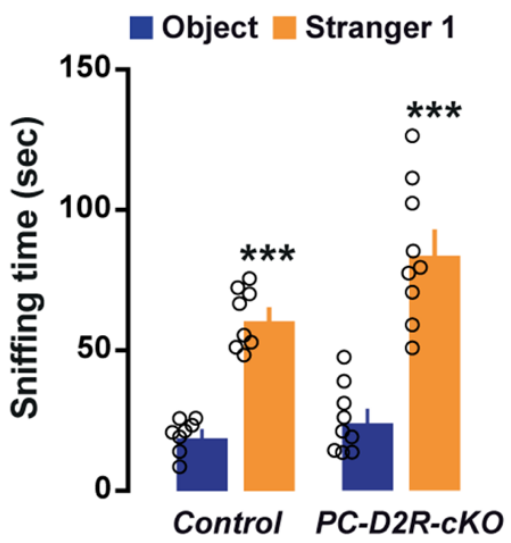

Total time

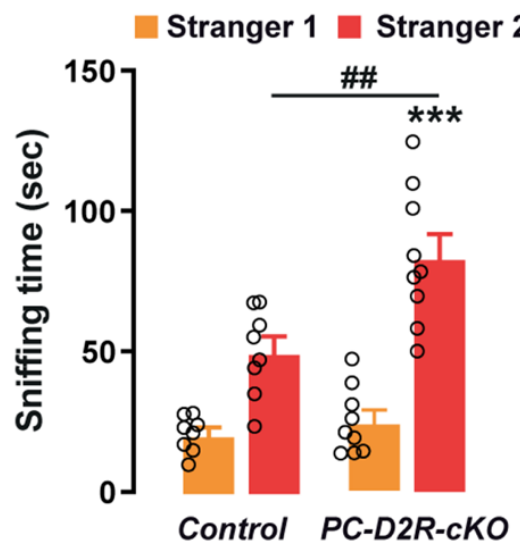

b

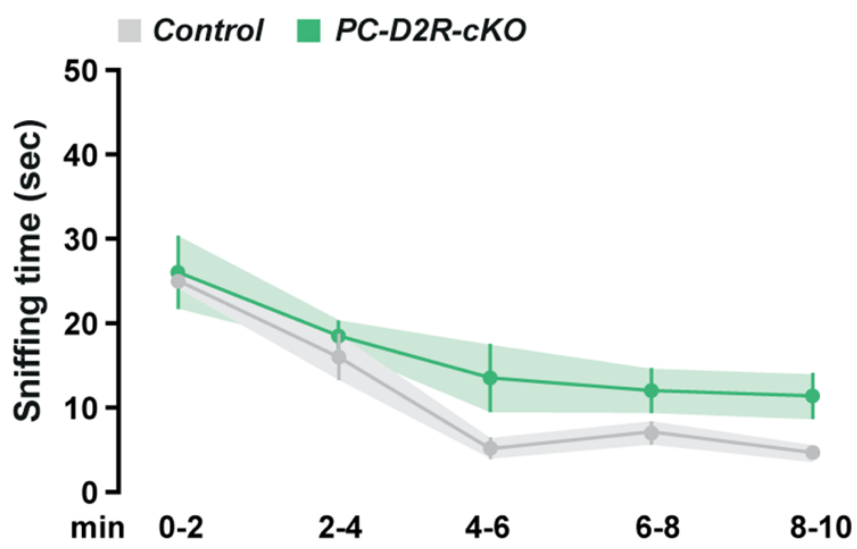

d

Time interacting with Stranger 2

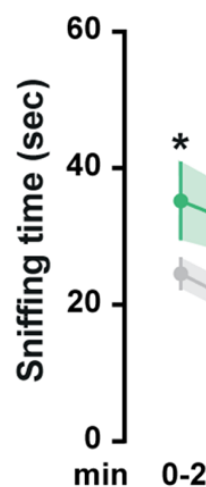

$* *$

$\min \quad 0-2$

$2-4$

4-6

6-8

8-10 


\section{Cutando et al Figure 6}

a

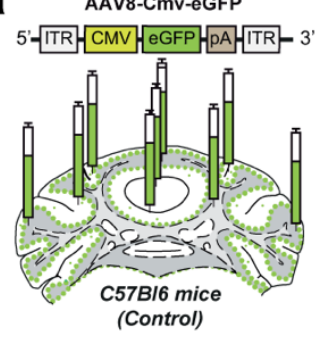

AAV8-Cmv-mDrd2-IRES-eGFP 5- ITR CMV Drd2 EGFPA ITR-3'

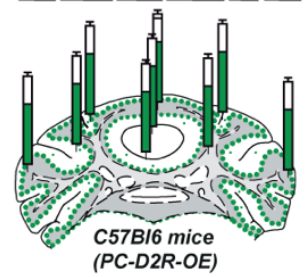

e

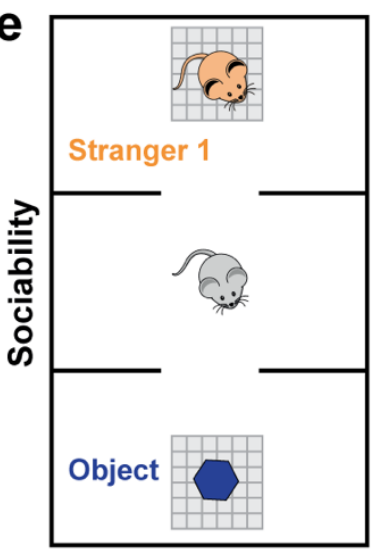

g

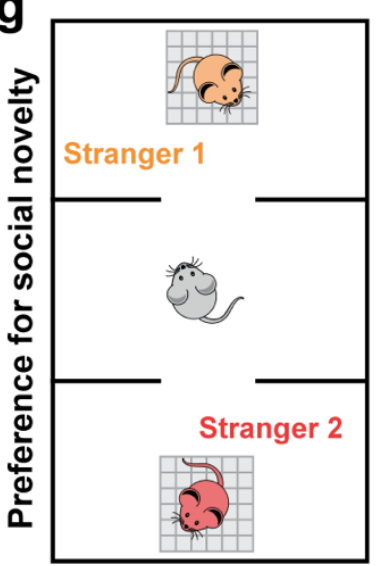

b
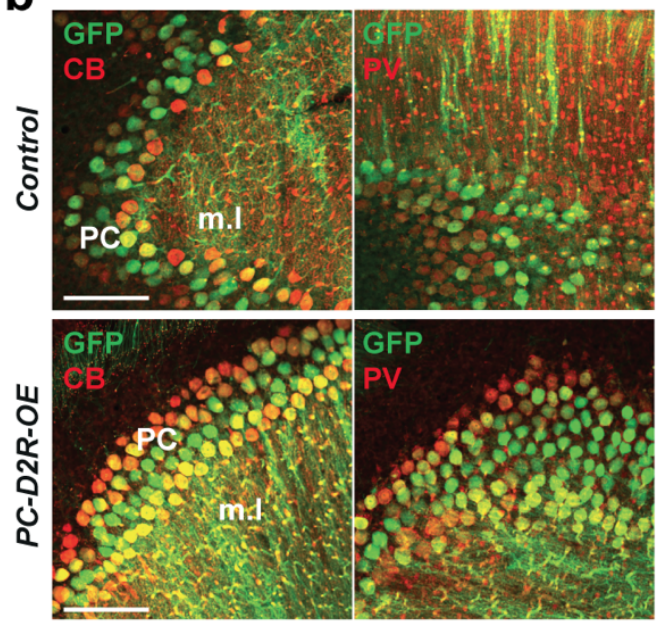

Total time

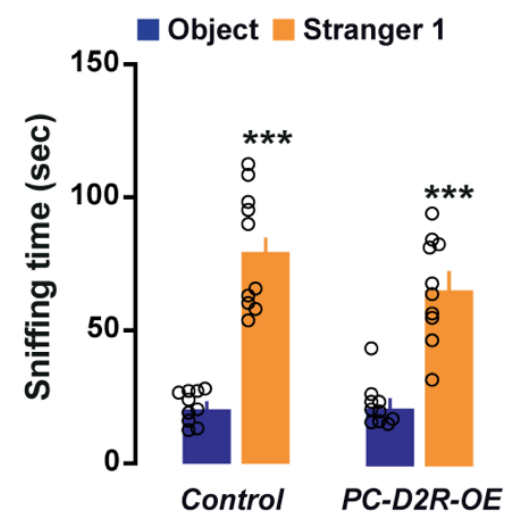

Total time

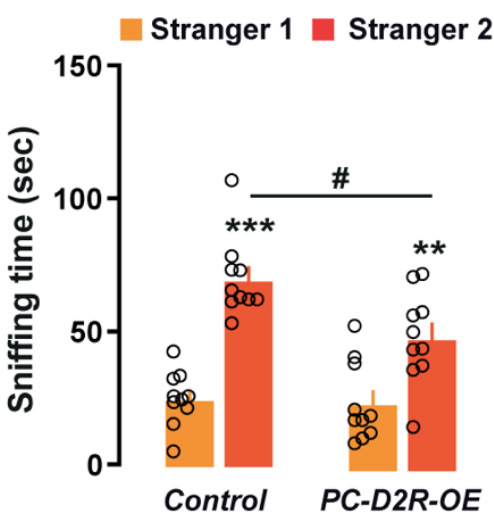

f

h c

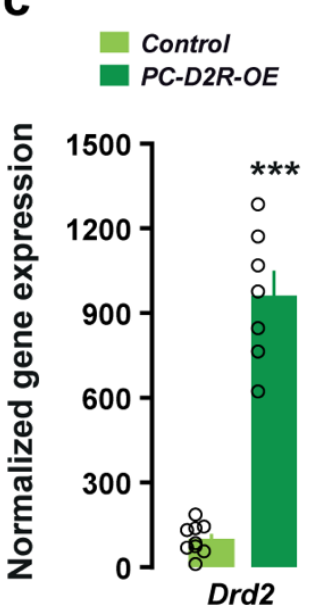

d
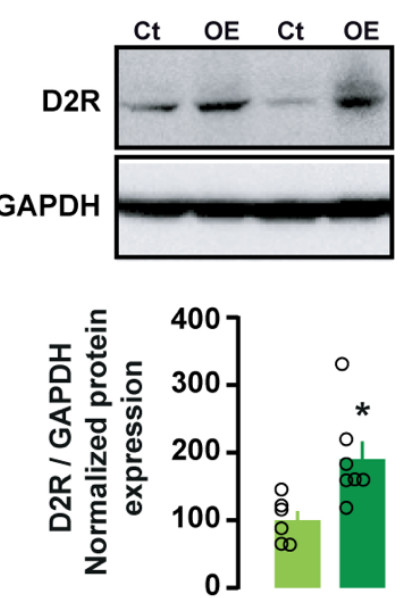

Time interacting with Stranger 1
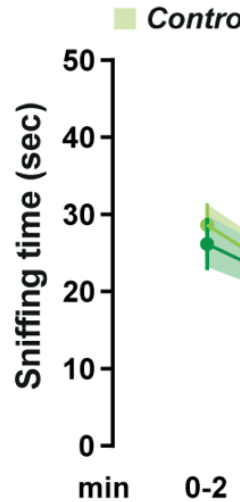

Time interacting with Stranger 2

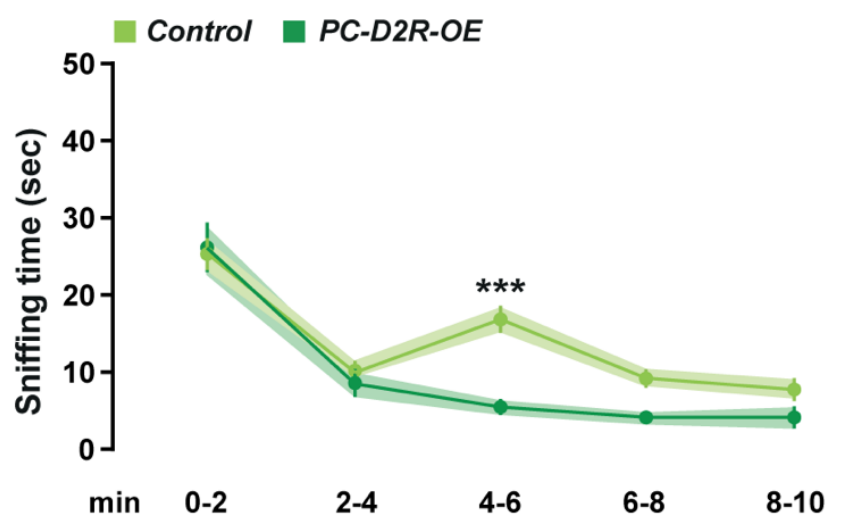

